\title{
الانغماس الوظيفي وعلاقته بالازعاجات اليومية لدى المرشدين التزبويين
}

د . سالم هميد عبيد)(*)

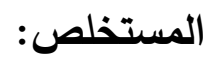

هدف البحث إلى تعرف الانغماس الوظيفي وعلاقته بالإزعاجات اليومية

لدى المرشدين التربوين وقد استعمل الباحث المنهج الوصفي وبلغت عينة البحث (200) مرشدا ومرشدة تربوية، وقد استعمل الباحث مقياسين هما: مقياس الانغماس الوظيفي والثاني مقياس الإزعاجات اليومية، وقد تم التحقق من الصدق (الظاهري، والبناء) والثبات لكلا المقياسين وباستعمال الاتساق الداخلي (الفاكرونباخ) وتوصل البحث إلى عدة نتائج أهمها:- إن متوسط الانغماس الوظيفي لدى المرشدين التربويين كان (31.8350) وهذا يشير إلى مستوى أعلى مقارنة مع المتوسط النظري البالغ (30) وإن مستوى الإزعاجات اليومية لديهم (157.0800) وهو مستوى عالي يذل على تمتع العينة بالإزعاجات اليومية مقارنة مع المتوسط النظري البالغ (150) وبين البحث عدم وجود فروق ذات دلالة إحصائية بين المرشدين التربوين في الانغماس الوظيفي تعزى لمتغير الجنس، أما في الإزعاجات اليومية فقد أظهرت النتائج وجود فروق ذات دلالة إحصائية بين المرشدين التربويين في مستوى الإزعاجات اليومية تعزى لمتغير الجنس ولصالح الإناث، كما دلت النتائج على وجود علاقة ارتباطيه موجبة دالة بين الانغماس الوظيفي والإزعاجات اليومية. الكلمات المفتاحية: الانغماس الوظيفي، والإزعاجات اليومية. (*) حاصل على درجة الدكتوراه في التربية- جامعة بغداد- العراق. 
مجلة وادي النيل للاراسات والبحوث الإنسانية والاجتماعية ـ مجلة علمية محكمة

(ISSN : 2536 - 9555)

\title{
Job Involvement And Relationship To Daily Hassles Among Educational Counselors
}

\begin{abstract}
:
The study aimed to identify Job Involvement and its relationship to Daily Hassles among Educational Counselors, the researcher used descriptive approach and reached the study sample (200) Educational Counselors. The researcher instruments used are: Job Involvement scale and second Daily Hassles scale has been checked and validtiy (face, and construction) and consistency of the instruments using internal consistency Cronbach's alpha The study came to the following findings: - The degree of Job Involvement Daily Hassles among Educational Counselors was (31.8350) this refers to a higher level, compared with the The theoretical average of (30) and that Daily Hassles level have (157.0800), a high level indicates that the enjoyment of the sample with professional competence, compared with the The theoretical average of (150) and the study showed that there the results showed no significant statistical differences between Educational Counselors in the level of Job Involvement due to the variable sex, were significant statistical differences between Educational Counselors in Daily Hassles due to the variable sex, and the results indicated the presence of a positive correlation between Daily Hassles and Job Involvement relationship.
\end{abstract}

Key words: Daily Hassles, Job Involvement.

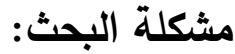

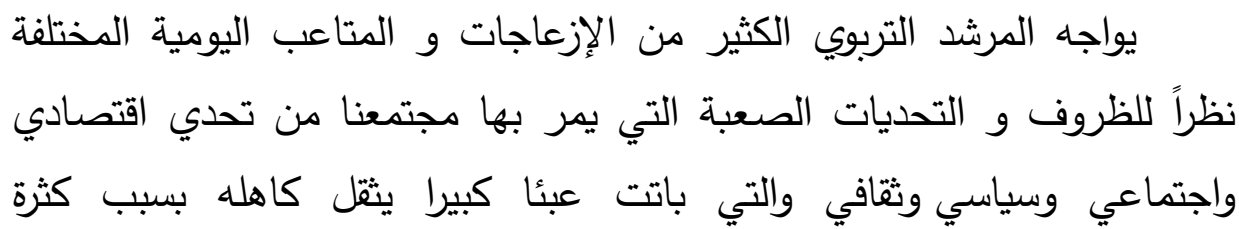


الإزعاجات والمتاعب اليومية وتكرارها وتراكها، مثل الإزعاجات و المتاعب

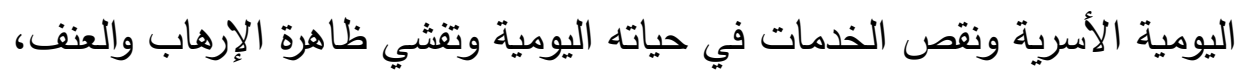

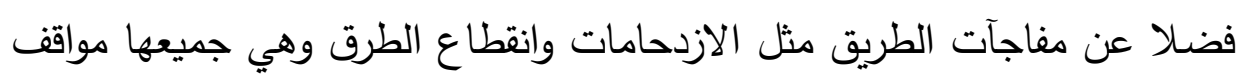

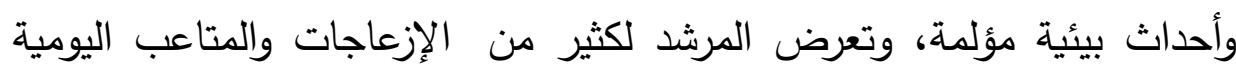

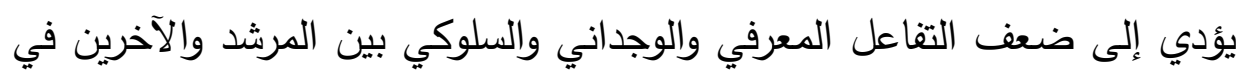
المواقف الإرشادية وبالتالي يضعف دوره مما يؤدي إلى فقدان العلاقة الإرشادية بين المرشد والمسترشد أساسها الصحيح ل والانغماس الوظيفي كمفهوم يعبر على نحو عام عن أهمية الدور الذي

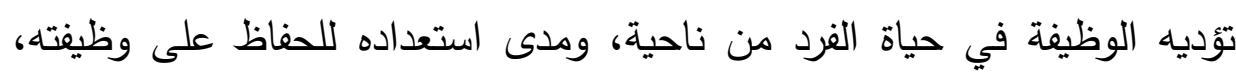

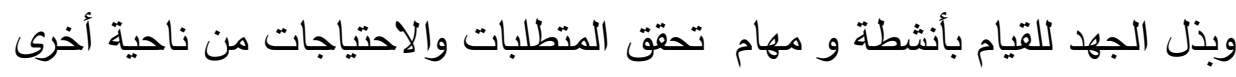

$$
\text { (الفضلي، 2001: (الفيل 106). }
$$

ويرى (Bass, 1965) أن شعور الفرد بتقديم مساعدة حقيقية يؤدي به

إلى النجاح في عمله وأن لديه الفرصة للمشاركة الحقيقية و الفعلية والتهيئة

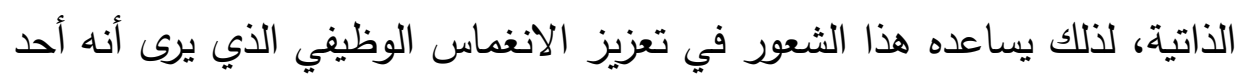

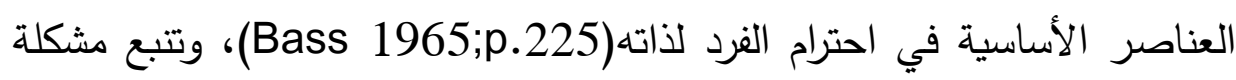

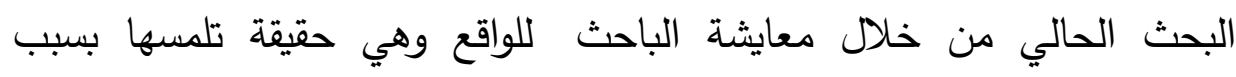

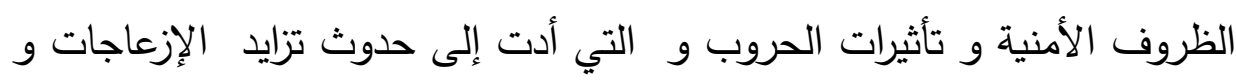

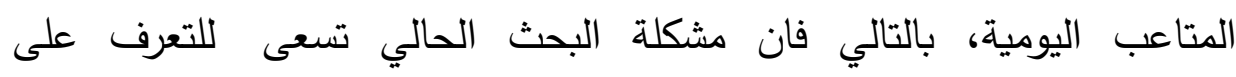
الانغماس الوظيفي وعلاقته بالإزعاجات اليومية لدى المرشدين التربويين، لأنه لم لم الئل

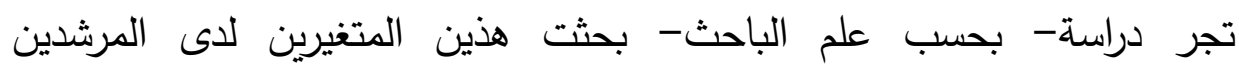
التربويين. 


\section{مجلة وادي النيل للاراسات والبحوث الإنسانية والاجتماعية ـ مجلة علمية محكمة}

(ISSN : 2536 - 9555)

أهمية البحث:

توصف العملية الإرشادية بأنها عملية فنية و علمية دقيقة، فالإرشاد مهنة

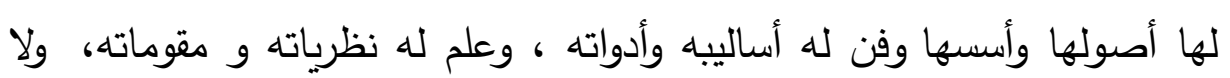
يعني نقل المعارف والمعلومات إلى المسترشد، بل ينبغي لمن يمارسها أن تكون لديه المهارات والقدرات، وان المرشد الذي يقوم بها يؤديها لمدة طويلة ومع مجموعات متنوعة من المسترشدين • (الحراحشة، 2001: 6).

ويعتمد نجاح العملية الإرشادية في المؤسسات التعليمية و التربوية إلى مدى بعيد على مواجهة الإزعاجات والمتاعب اليومية من قبل المرشدين التربوين ومدى ولئ تفاعلهم وانغماسهم في دورهم الإششادي، ويرتبط ذلك بامتلاكهم مجموعة من المواصفات التي تجعلهم قادرين على مساعدة الآخرين، ويمتلكون سمات عقلية و انفعالية واجتماعية وخلقية وبدنية، الذين يتمكنون من دمج معارفهم الأكاديمية بسماتهم الشخصية، ومهاراتهم وقدراتهم للمساعدة في عملية الإرشاد، و التعامل مع الازعاجات والمتاعب اليومية بفاعلية، يظهر قدرتهم على التوافق مع المواقف الإرشادية المختلفة، وتواصلهم مع الآخرين، فقدرة المرشد التربوي في التعامل مع الإزعاجات والمتاعب اليومية له تأثير إيجابي على مستوى الخدمات الإرشادية Springetal, ) المقدمة من خلال الاستجابة لحالات المسترشدين واحتياجاتهم .$(1995 ;$ p. 1015

فالانغماس الوظيفي يبين مدى وعي وإدراك الفرد لأهمية وظيفته وتأثيرها في احترامه لذاته وإحساسه بالتقدير والاحترام (Siegle,1969) ويعد الانغماس الوظيفي واحد من أكثر الأدوات الفعالة التي تستخدم لزيادة إنتاجية الموظفين وتعزيز مشاركتهم والالتزامهم بقواعد العمل. (Khan.et .al: 2010;p.252) 
الانغماس الوظيفي يؤدي إلى الرضا الوظيفي والالتزام الوظيفي، والأداء الوظيفي (Bass 1965;p.226) وللانغماس الوظيفي تأثير كبير على إنتاجية

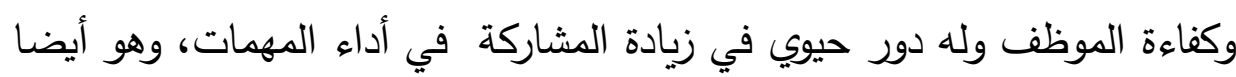

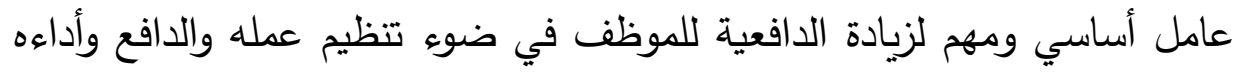
وبالتالي يؤدي إلى زيادة النمو المهني و الثعور بالارتياح في بيئة العمل. والحياة اليومية مليئة بالإزعاجات (Sonnentag \& Kruel , 2006; p.198) والمتاعب اليومية التي يواجهها الفرد في داخل الأسرة أو في بيئة العمل، وتؤثر ملأه

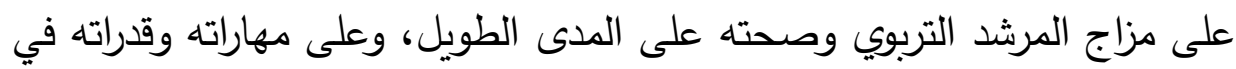

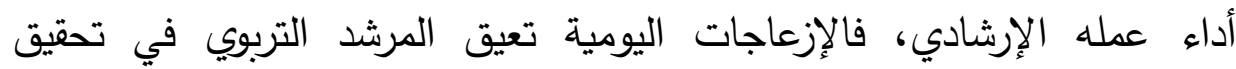

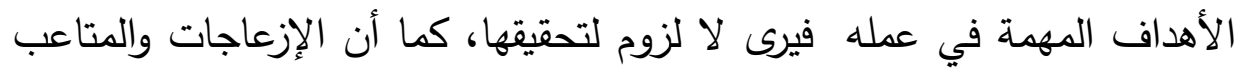

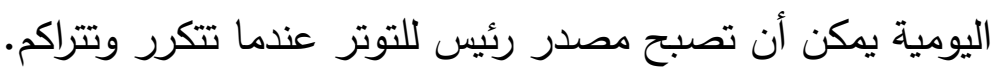

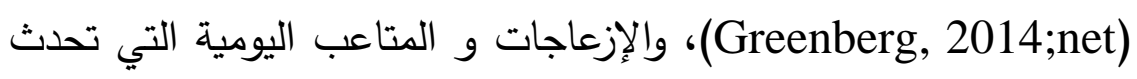
على نحو متكرر في العلاقات الثخصية أو جوانب الحياة اليومية الروتينية يكون لها تأثير على الفرد أو الحياة الأسرية. ( Malia, et al.1987;p.77) ويرى الباحث الانغماس الوظيفي للمرشد التزبوي وقدرته على مواجهة

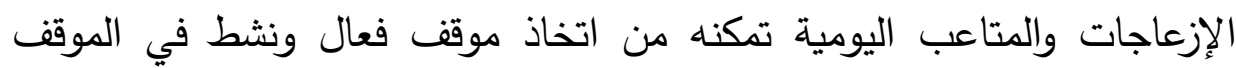
الإرشادي واستجابة لاحتياجات المسترشدين و وعي مرشدي ومرشدات المدارس

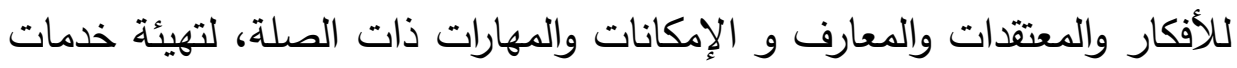

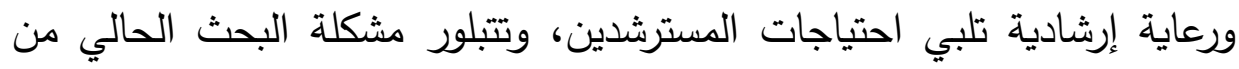

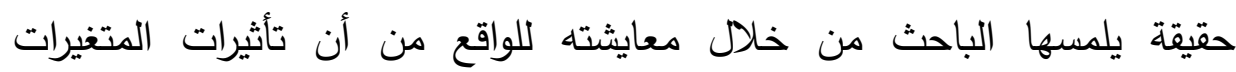

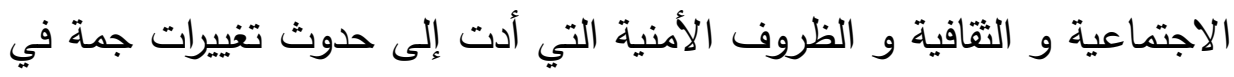
واقع الحياة اليومية أثرت في الانغماس الوظيفي وعلاقته بالإزعاجات اليومية. 


$$
\begin{aligned}
& \text { أهداف البحث: } \\
& \text { يستهدف البحث الحالي التعرف على: } \\
& \text { - مستوى الانغماس الوظيفي لدى المرشدين التربوين. } \\
& \text { - مستوى الإزعاجات اليومية لدى المرشدين التربوين. }
\end{aligned}
$$

- - العَلاقة بين الانغماس الوظيفي والإزعاجات اليومية لدى المرشدين

$$
\text { التربوين. }
$$

- - الفروق ذات الدلالة الإحصائية في الانغماس الوظيفي لدى المرشدين

$$
\text { التربوين على وفق متغير : الجنس (ذكور / إناث). }
$$

- - الفروق ذات الدلالة الإحصائية في الإزعاجات اليومية لدى المرشدين

$$
\text { حدود البحث: التربين على وفق متغير : الجنس (ذكور / إناث). }
$$

يقتصر البحث الحالي على المرشدين التربويين (الإناث و الذكور) المستمرين في الخدمة في المدارس الثانوية والمتوسطة والإعدادية في المديريات العامة لتربية محافظة بغداد التابعة لوزارة التربية للعام الدراسي (2015-

\section{تحديد مصطلحات البحث:}

1-الانغماس الوظيفي/ Job Involvement عرفه كل من:

- بأنه: التعرف النفي الذي يتعزز بالحالة (Kanungo, 1982) المعرفية وتلبية الاحتياجات الثخصية المهمة للفرد من خلال الوظيفة.

(Kanungo, 1982) 
بأنه: انشغال الفرد بوظيفته معرفيا وسلوكيا (Paullay.et al,1994) واستغراقه بها. (Paullay.et al,1994.p.225) برانهان

(Leong,2003) -

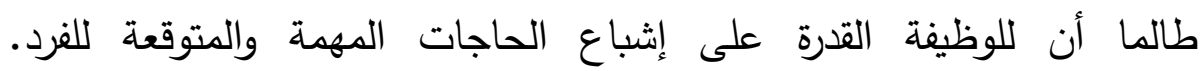
(Leong,2003,p.3)

- واعتمد الباحث تعريف كاننجو (Kanungo, 1982) تعريفا نظرياً لمفهوم الانغماس الوظيفي للبحث الحالي.

- ويعرف الباحث الانغماس الوظيفي إجرائيا بأنه الدرجة الكلية التي

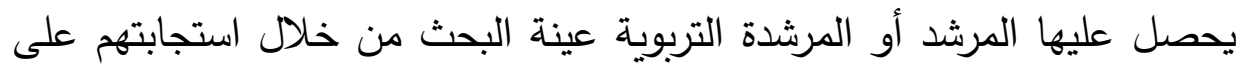
فقرات مقياس الانغماس الوظيفي الذي اعتمده الباحث والمستخدم في هذا البحث. 2- الإزعاجات اليومية Daily Hassles عرفها كل من:

(Kanner, et al., 1981) بشكل متواتر و متكرر يوما بعد يوم وتصبح مطالب محبطة و مزعجة التي Kanner, et al., ).تصبح إلى حد ما نمط من التعاملات اليومية مع البيئة (1981;p.23

- (Folkman, \& ,Lazarus1989) -

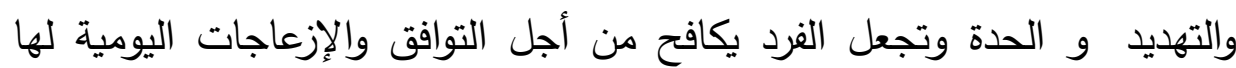

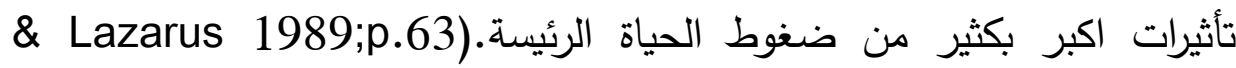
.(Folkman, 
- (Fink,2010) الضغوط الخفيفة التي تؤدي إلى تهديدات ثم إلى

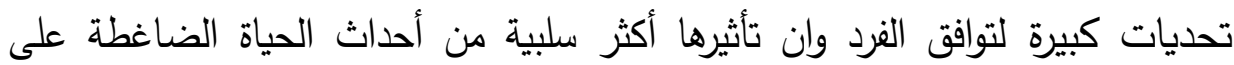

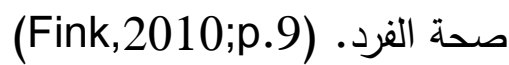

-واعتمد الباحث تعريف (Kanner, et al., 1981) تعريفا نظرياً لمفهوم الإزعاجات اليومية للبحث الحالي.

- ويعرفها إجرائيا بأنها الدرجة الكلية التي يحصل عليها المرشد أو المرشدة التربوية عينة البحث من خلال استجابتهم على فقرات مقياس الإزعاجات اليومية الذي أعده الباحث والمستخدم في هذا البحث.

\section{الإطار النظري}

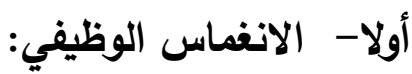

يبين الانغماس الوظيفي أهمية الوظيفة في حياة الفرد، فالفرد المنغدس في

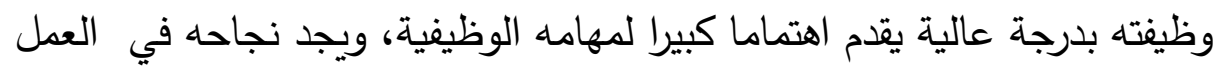

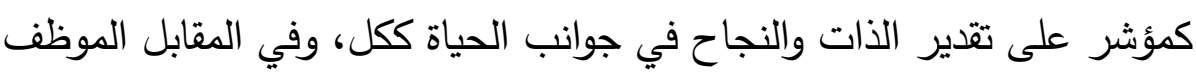
المنغمس بوظيفته بدرجة أقل يشعر بأن هناك أشياء واهتمامات أخرى في الحياة أهم من وظيفته، فالانغماس الوظيفي يوصف بأنه مدى ارتباط الفرد بوظيفته، التي لئي تؤثر على أدائه ونشاطه فى مختلف مجالات الحياة.

(Elias\& Mittal 2011,p. 305- 306)

كما يبين الانغماس الوظيفي درجة اهتمام الفرد بعمله بوصفه أهم شيء في

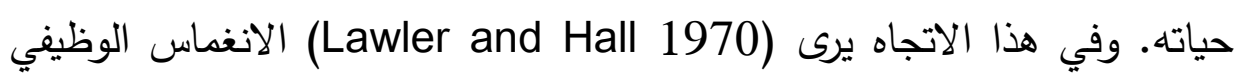

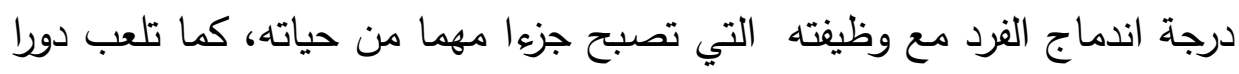
مؤثرا وأساسيا في تحديد هويته وذاته من خلال الفرصة التي يوفرها العمل للفرد 
لإثباع حاجاته الأساسية، كما يوضح الانغماس الوظيفي درجة مشاركة الفرد في عمله واحترام ذاته واستقلالها و التحكم بها وإشباع حاجاته.

(Lawler and Hall1970.p. 305)

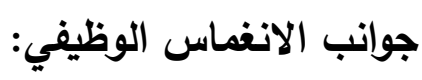

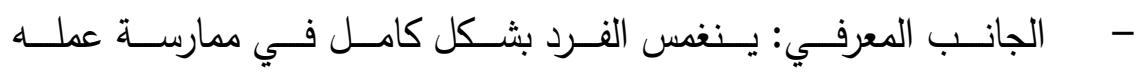
(Rothbard, 2001: 655) بشكل كبير على المهمة التي أعطيت له. (Rothbard, 2001: 655). - - الجانب الوجداني: يعني الانغماس الوجداني بوجود علاقة قوية بين العواطف، والأفكار ، ومشـاعر الفرد وبين وظيفته (Kahn, 1990: 700)

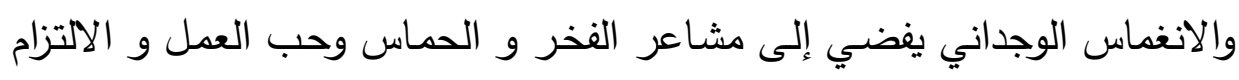

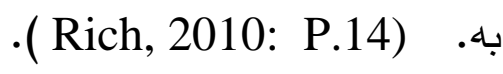

- - الجانب السلوكي: توجيـه الطاقات الماديـة للفرد مـن اجل استكمال مهمة معينة و يتراوح بين الانغماس الخامل و الانغماس النشط. (Rich, 2010: P. 702)

العوامل المؤثرة في الانغماس الوظيفي: يتأثر الانغماس الوظيفي بعوامل عدة هي: - العوامل الثخصية: مثل (الدوافع والاتجاهات والقيم و الثعور بالنجاح). - العوامل الوظيفية: مثل (استقلالية الوظيفة والحوافز والتتوع وتوصيف المهام والمشاركة مع زملاء الوظيفة). - العوامل الاجتماعيـة: مثل (المشـاركة في اتخـاذ القرارات، والعمل مـع الآخرين). (قاسم، 2012: ص 95-97). 


\section{مجلة وادي النيل للاراسات والبحوث الإنسانية والاجتماعية ـ مجلة علمية محكمة}

(ISSN : 2536 - 9555)

\section{الانغماس الوظيفي ونظرية الدور:}

لقـد ربط (1990, Kahn) الانغــاس الـوظيفي بنظريـة الـدور، وتـدرس

نظرية الدور السلوك لدى الفرد الذي يتثكل بتأثير قواعد ومطالب الأفراد الآخرين,

(Kahn, 1990: 701)

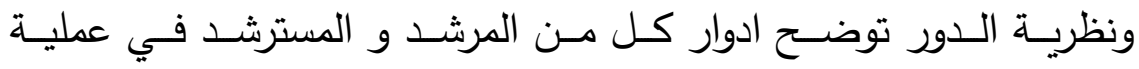

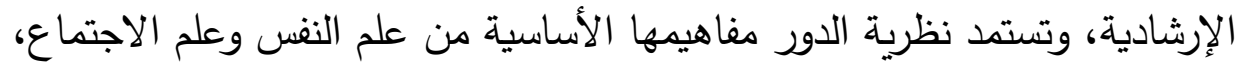

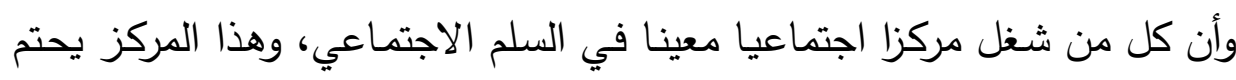

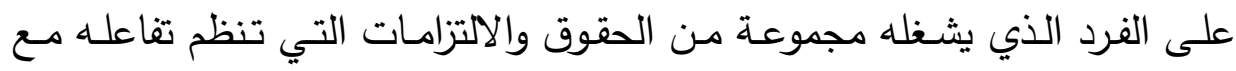

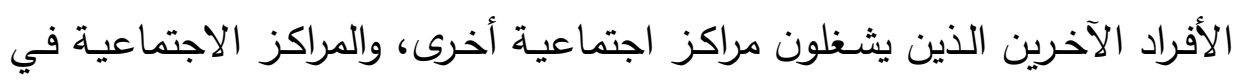
المجتمع الحديث تحدد أساسا على أساس اقتصادي اجتماعي.

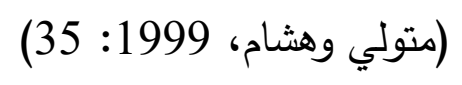

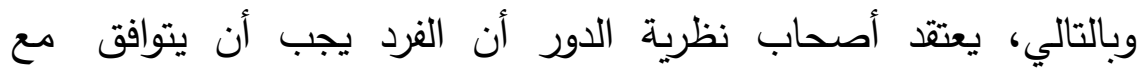

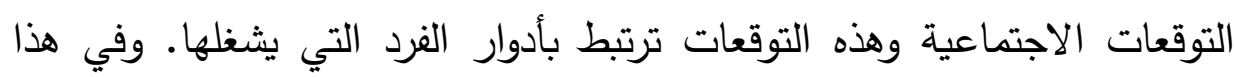
المعنى، يمكن توقع سلوك الفرد من خلال تحليل أدواره .

.(Biddle \& Thomas, 1966:p.4)

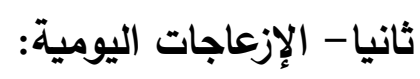

تكثر في الحياة اليومية الإزعاجات والمتاعب المتكررة اليومية التي تصادف الفرد، والإزعاجات اليومية تتمثل بالمشاكل العملية المزعجة والمعوقات الصغيرة لتقدم حياته على أساس يومي، و خيبة الأمل المتكررة، والخلافات والمشاكل

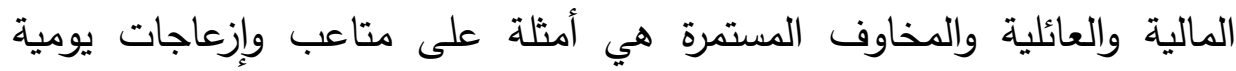

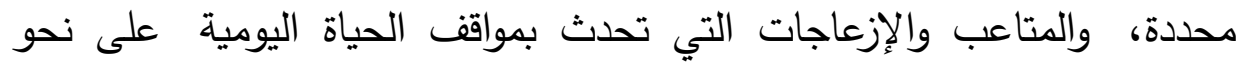

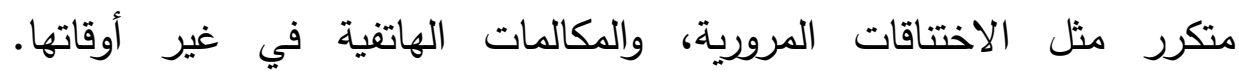


فالإزعاجات المتكررة تحدث متاعب للفرد فهي تمنعه من رؤية الأهداف المهمة وتمنع تحقيقها، وهي تكون في مسار العمل أو الحياة العائلية، وأن الإزعاجات اليومية تعد مؤشرا جيدا لتوافق الفرد في المواقف الاجتماعية، في ظل أحداث الحياة الكبرى. (Kanner, et al., 1981;p.25)

أشارت دراسة أجراها (DeLongis, et.al ,1988) بأن الإزعاجات والمتاعب اليومية أصبحت مؤشرا للضغوط وتظهر على الفرد مثل أعراض التوتر النفسي، وقد استعملت دراسات عديدة مصطلح الإزعاجات اليومية لقياس التوتر والإجهاد إما على نحو منفرد أو بالاشتراك مع مصطلح أحداث الحياة والتي

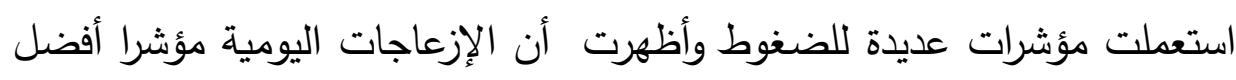
للضغوط من متغير أحداث الحياة. (DeLongis, et.al ,1988;p. 486) الإزعاجات اليومية يجب أن تتم دراستها من حيث طبيعتها وتوقيتها وتكرارها وشدتها. (Kanner, et al., 1981;p.49) أراء المنظرين التي تناولت الإزعاجات اليومية: - كـانر (Kanner, et al., 1981) إن الإزعاجـات اليوميـة هي إزعاجـات و متاعب يوميـة متواترة تأتي يومـا بعد يوم في سياق حياة الفرد و و

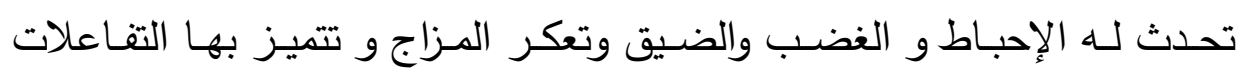
اليومية في التعامل والتواصل مع الآخرين وفي البيئة المحيطة به، فتسبب الهيجان والغضب وعدم التحمل وعدم سعة الصدر ، وتكون بشكل متاعب وإزعاجات يومية مثل فقدان الأشياء كالمفاتيح أو الأوراق المههـة أو الاختتاقات مروريـة و الازدحام

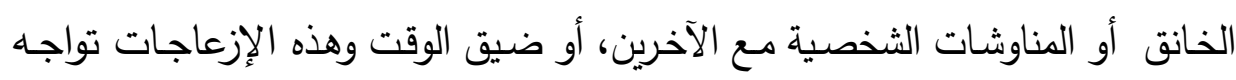
الأفراد العاديين كجزء من سياق الحياة اليومية. (Kanner, et al., 1981;35) 
- لازاروس وفوكمان (Folkman, \& Lazarus , 1989): لقد وضـا تصورا عن الإزعاجات و المتاعب اليومية التي تحصل للفرد من خلال التفاعل مع روتين ومواقف الحياة اليومية التي تهدد رفاهية الفرد وتكون التفاعلات مشتركة التهاته

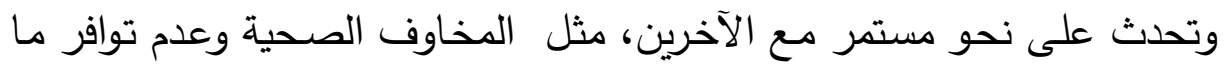

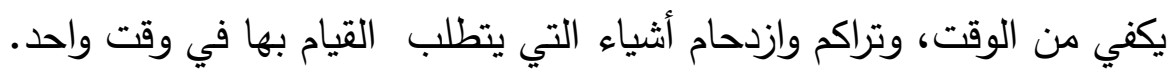
(Folkman, \& Lazarus :1989;p.38)

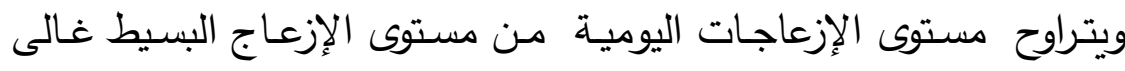

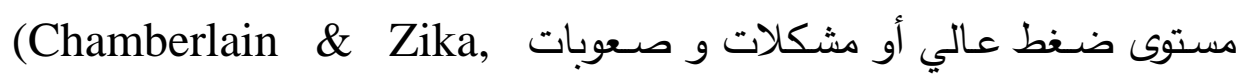

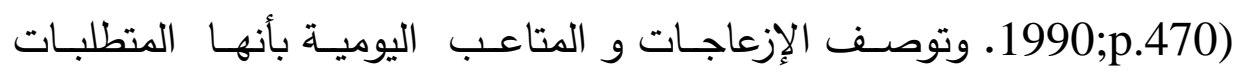

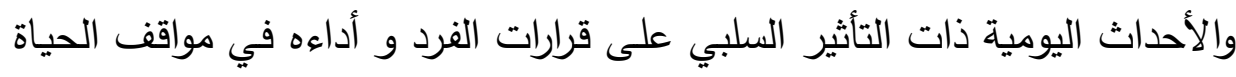
اليومية (Stone, 2007;p.9). وتبدو الإزعاجات على نحو مضايقات ومتطلبات

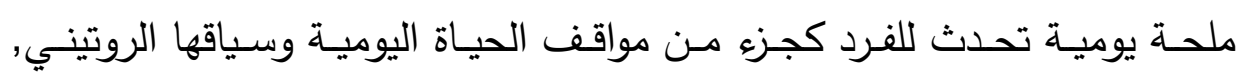

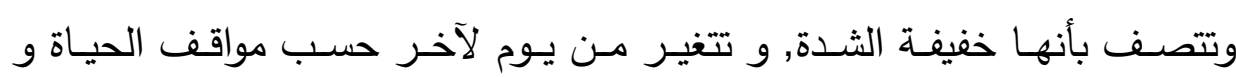

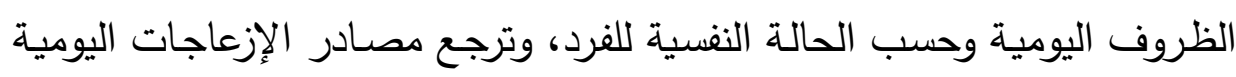

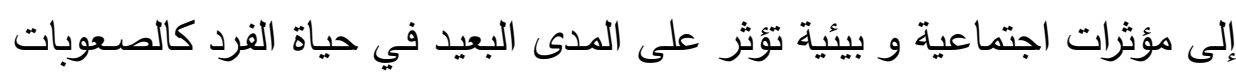
المالية. (Ranchor \& Sanderman, 2000; p.16).

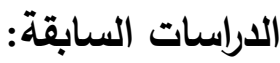

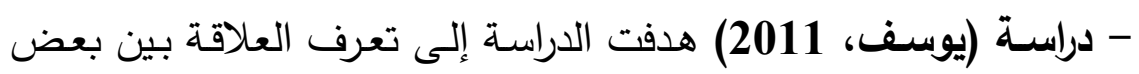

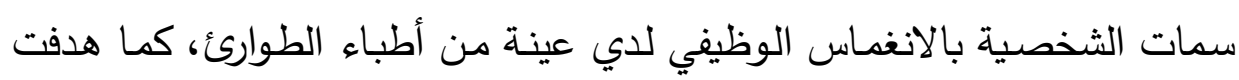

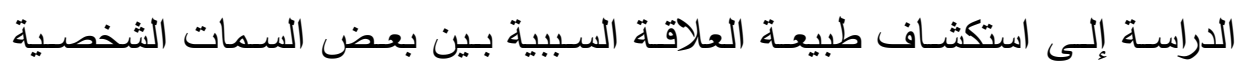

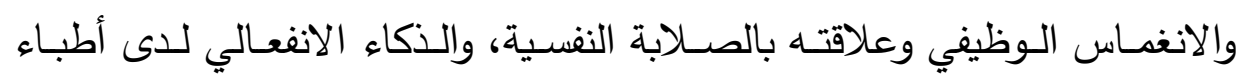

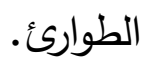


بلغت عينة الدراسة (262) من أطباء الطوارئ من كلا الجنسين، وكانت

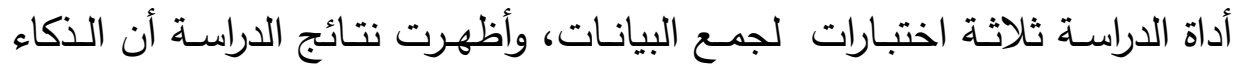
الانفعالي والصلابة النفسية لهما تأثير مباشر على الانيات التغماس الوظيفي. (يوسف،

- - دراسة (Swaran, et al. 2011) هدفت الدراسة إلى تعرف العلاقة

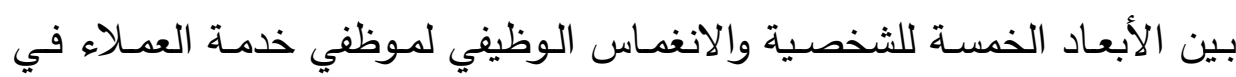

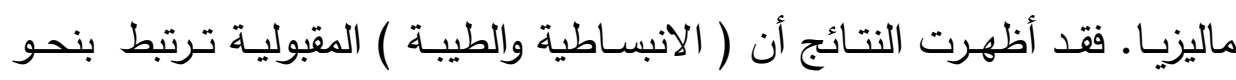

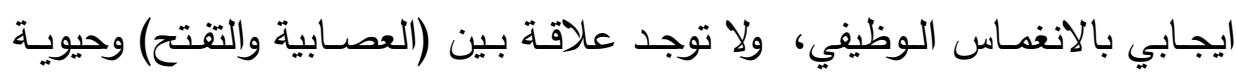
الضمير و الانغماس الوظيفي، وعلى نحو عام تبين أن هناك علاقة بين الأبعاد

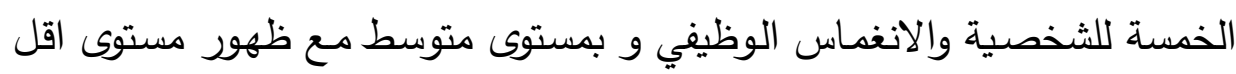
من الجيد من الانغماس الوظيفي لدى أفراد العينة. (Swaran, et al. 2011;p.154) - دراسـة (Kanner et al,1981): هدفت الدراسة للمقارنة بين طريقتين لقياس الضغط النفسي بين الإزعاجات اليومية مقابل أحداث الحياة ـ بلغت العينة الدراسـة (100) من ولايـة كاليفورنيا (52) إنـاث و (48) الذكور تئراوح أعمارهم

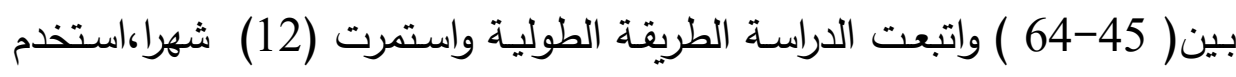
الباحثون اختبارات هوبكنز ومقياس برادبورن وتطبيقه كل شهر لمدة تسعة أشهر ،

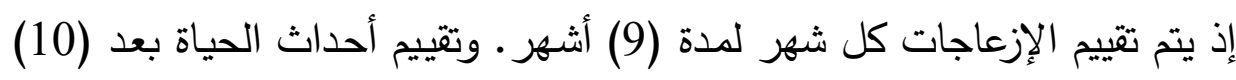

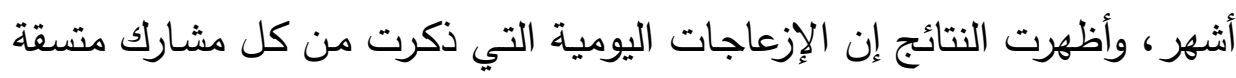

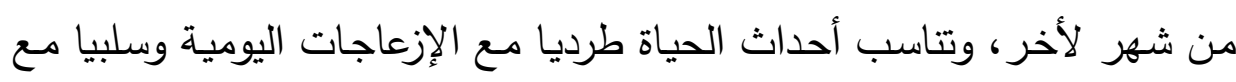

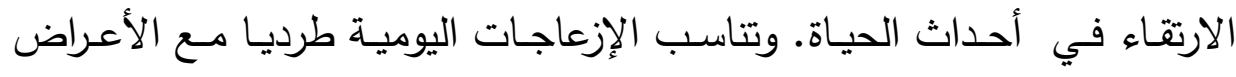

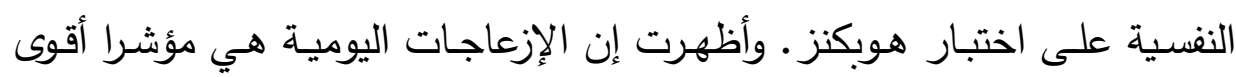
على الأعراض النفسية من أحداث الحياة. (Kanner,et al,1981;p.1-39) 


\section{مجلة وادي النيل للاراسات والبحوث الإنسانية والاجتماعية - مجلة علمية محكمة}

(ISSN : 2536 - 9555)

- دراسـة (Garison,1990): هدفت الدراسة إلى تعرف اثر الإزعاجات

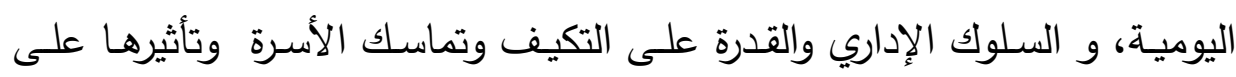

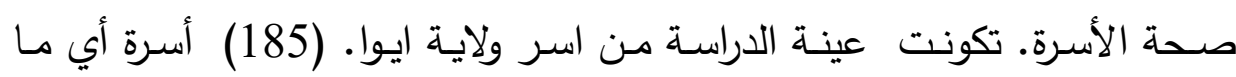
يقرب من(60\%) الذكور • وأكثر من(90\%) من العينة لهم خلفية عرقية أو إثنية،

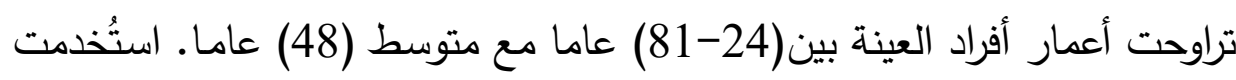

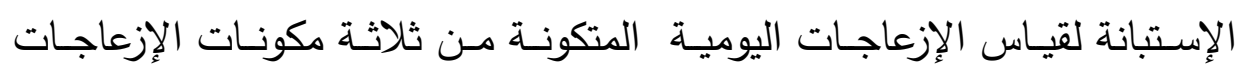

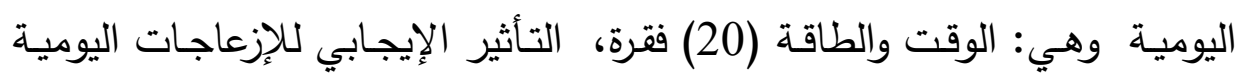

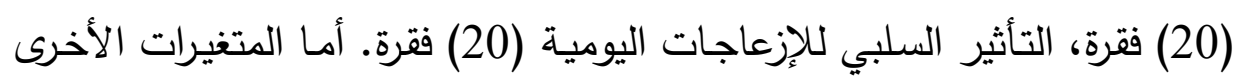

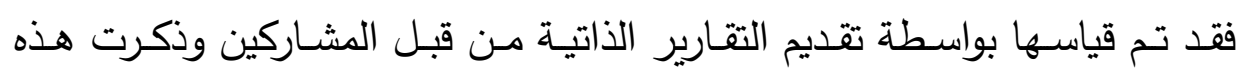

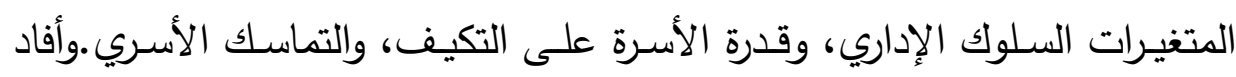

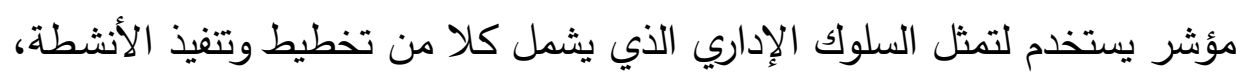

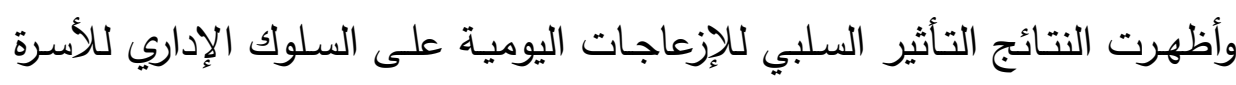
وقدرة الأسرة على التكيف، والتماسك الأسري.

(Garison,1990;p.55-107)

- منهجية البحث وإجراءاته: - - منه منهج البحث: اتبع الباحث المنهج الوصفي لتحقيق أهداف بحثه. مجتمع البحث: تكون مجتمع البحث من المشدين التربويين (الذكور/

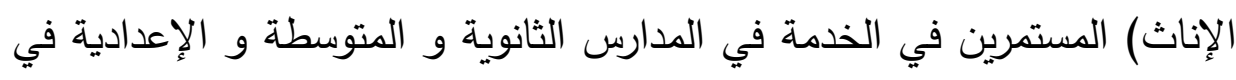

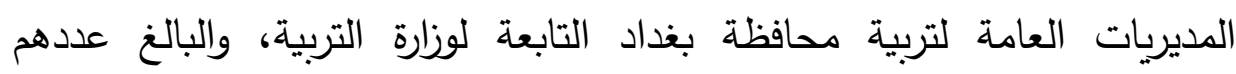
(1476)(1) مرشد /مرشدة تربوية، بواقع (487) مرشد تربوي و(889) مرشدة لغرانة

$$
\text { تربوية للعام الدراسي (1476) مرئد (مندة تربوبة، بوانع }
$$

(1) أم الحصول على هذه البيانات من شعبة الإرشاد التربوي في وزارة التربية. 
عينة البحث الأساسية: بلغت عينة البحث الأساسية من (200) مرشد/ مرشدة تربوية اختيروا بالأسلوب الطبقي العشوائي ولما يتتاسب تقربباً مع عددهم في مجتمع البحث و حسب متغير الجنس، الجدول (1) يوضتح ذلك. الجدول (1) عينة البحث الأساسية للتطبيق موزعه بحسب الجنس

\begin{tabular}{|c|c|c|c|}
\hline \multirow{2}{*}{ المجموع } & \multicolumn{2}{|c|}{ الجنس } & \multirow{2}{*}{ مديريات } \\
\hline & إناث & ذكور & \\
\hline 21 & 16 & 5 & الرصافة الأولى \\
\hline 40 & 27 & 13 & الرصافة الثانية \\
\hline 23 & 12 & 11 & الرصافة الثالثة \\
\hline 28 & 20 & 8 & الكرخ الأولى \\
\hline 41 & 29 & 12 & الكرخ الثانية \\
\hline 47 & 25 & 22 & الكرخ الثالثة \\
\hline 200 & 129 & 71 & المجموع \\
\hline
\end{tabular}

أدوات البحث:

أولا- مقياس الانغماس الوظيفي:

بعد اطلاع الباحث على عدد من المقاييس التي تتعلق بالانغماس الوظيفي، وجد أن أنسب الأدوات لبحثه هو مقياس كاننجو (Kanungo, 1982) كونه اعد لقياس الانغماس الوظيفي. 
- وصف مقياس الانغماس الوظيفي: يتكون المقياس بصورته الأصلية من

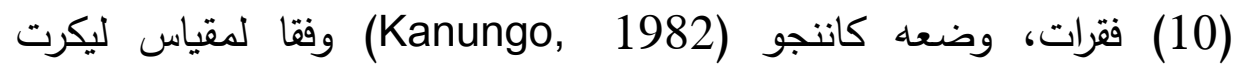
الخماسي يتدرج من موافق بشدة (5) إلى غير موافق بثدة (1) ويتمتع الاختبار

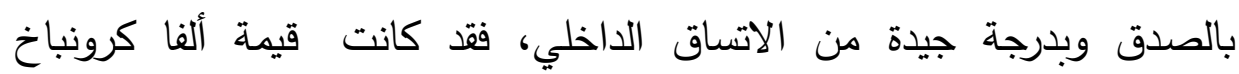
هي(0.81)، مما يدل على موثوقية المقياس. (Khan),

إجراءات مقياس الانغماس الوظيفي للبحث الحالي:

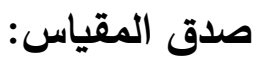

1- (Kanungo, دق الترجمة: قام الباحث بترجمة مقياس كاننجو

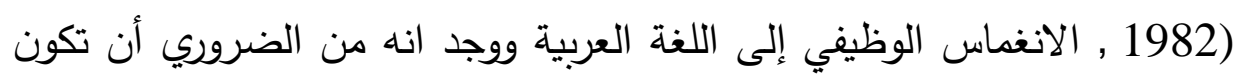

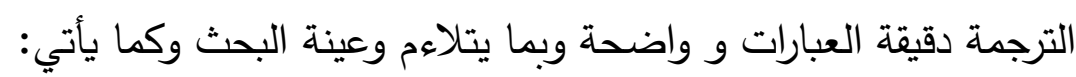
قام الباحث بترجمة النسخة الأصلية من المقياس وعرضت النسخة

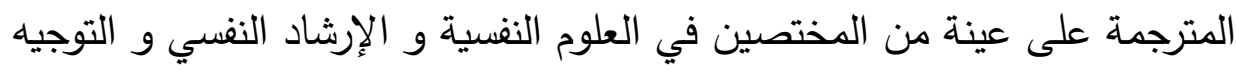

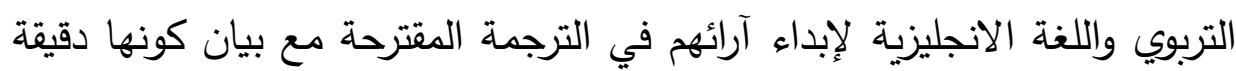

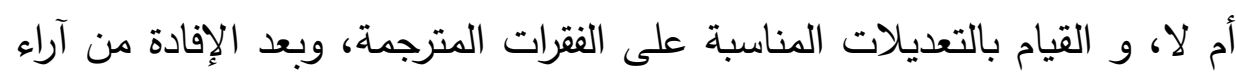

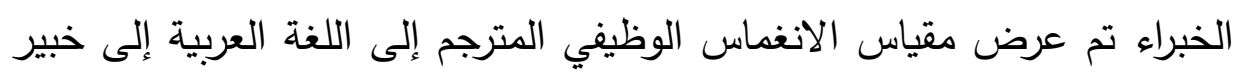

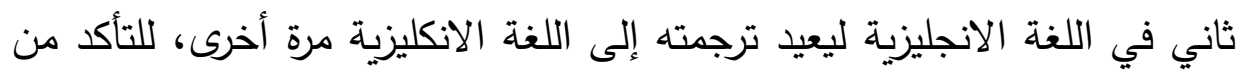

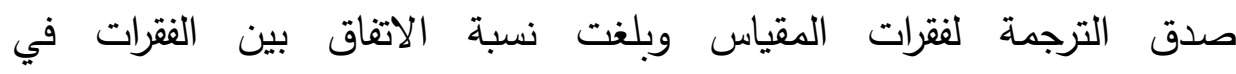
الترجمتين(82\%) وهي نسبة صالحة وفقا لرأي بلوم (إذا كانت نسبة الاتفاق بين المحكمين (75\%) فأكثر يمكن الوثوق في صدق القياس) (بلوم, 1983:126). 2-الصدق الظاهري: تحقق الباحث من الصدق الظاهري لمقياس الانغماس الوظيفي ومدى ملاءمة فقراته وتعليماته، عرضت فقراته في استبانه على (10)

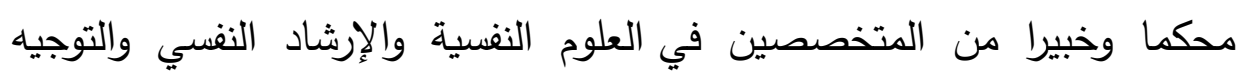


التربوي، وقد اعتمد الباحث موافقة (8) محكم معياراً لملاعمة الفقرات لعينة البحث وباستخدام (كا2)، وكانت قيمة (كا2) المحسوبة (6.40) أكبر من قيمة (كا2) الجدولية (3.84) بدرجة حرية (1) ولم تستبعد أي فقرة من المقياس، وبقي المقياس يتكون من (10) فقرات.

3- - صدق البناء: إن مؤشرات صدق البناء في المقاييس النفسية تبدو من خلال تمييز فقرات المقياس بين إجابات المجموعتين المتطرفتين على كل فقرة في Anastasi , 1997: (المقياس، و ارتباط الفقرة بالدرجة الكلية للمقياس( $\cdot($ p. 155

ويعتبر التحقق من قوة الفقرات التمييزيـة مؤشراً على صدق بناء المقياس، والتجانس بين فقراته، الذي يكثف عنه التحقق بارتباط كل فقرة بالدرجة الكلية للمقياس التي كانت دالة جميعها في المقياس بصورته النهائية. - التحليل الإحصائي لفقرات مقياس الانغماس الوظيفي: يؤكد خبراء القياس النفسي على الخصائص السيكومترية التي ينبغي التحقق منها في فقرات المقاييس هي القوة التمييزية للفقرات ومعاملات صدقها، لذلك تم حساب هذه

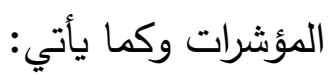
قوة تمييز الفقرات: لتحقيق ذلك طبق المقياس على عينة سحبت من مجتمع البحث مكونة من (400) مرشدا/ مرشدة تربوية، جدول (2). 
مجلة وادي النيل للاراسات والبحوث الإنسانية والاجتماعية ـ مجلة علمية محكمة

(ISSN : 2536 - 9555)

الجدول (2) عينة التحليل الإحصائي لمقياسي البحث

\begin{tabular}{|c|c|c|c|}
\hline \multirow[t]{2}{*}{ المجموع } & \multicolumn{2}{|l|}{ الجنس } & \multirow[t]{2}{*}{ مديريات التربية } \\
\hline & إناث & ذكور & \\
\hline 42 & 32 & 10 & الرصافة الأولى \\
\hline 81 & 55 & 26 & الرصافة الثانية \\
\hline 45 & 23 & 22 & الرصافة الثالثة \\
\hline 56 & 40 & 16 & الكرخ الأولى \\
\hline 82 & 58 & 24 & الكرخ الثانية \\
\hline 94 & 51 & 43 & الكرخ الثالثة \\
\hline 400 & 259 & 141 & المجموع \\
\hline
\end{tabular}

ويفضل حجم العينة المناسب في عملية التحليل الإحصائي في حساب قوة تمييز الفقرات أن لا يقل عن (400) فرد يتم تحديدهم بدقة من المجتمع الأصلي للبحث، وتكون نسبة (27\%) من أفراد العينة في تحديد المجموعتين المتطرفتين في الدرجة الكلية، بعد تطبيق المقياس على أفراد عينة التحليل الإحصائي رتبت إجاباتهم ترتيباً تنازلياً من أعلى درجة إلى أقل درجة كلية، ثم حددت المجموعتان المتطرفتان بنسبة (27\%) من المرشدين/ المرشدات التربويات عينة التمييز في كل مجموعة، فأصبح عدد المرشدين/ المرشدات التربويات في كل مجموعة (108) مرشد/ مرشدة تربوية، وبعد استخدام الاختبار التائي t-test لعينتين مستقلتين لمعرفة دلالة الفرق بين المجموعتين المتطرفتين في درجات كل فقرة من 
فقرات المقياس، فظهر أن جميع فقرات المقياس مميزة عند مستوى (0.05) لأن القيمة التائية المحسوبة كانت اكبر من القيمة التائية الجدولية (1.96) بدرجة حرية (214)، والجدول (3) يوضح القوة التمييزية لفقرات المقياس.

الجدول (3) قوة تمييز الفقرات لمقياس الانغماس الوظيفي

\begin{tabular}{|c|c|c|c|c|c|}
\hline \multirow{2}{*}{ التائية القيمة } & \multicolumn{2}{|c|}{ المجموعة الدنيا } & \multicolumn{2}{|c|}{ المجموعة العليا } & \\
\hline & الالحعرافي & الحسابي & الانحراف & الحسابي & ت \\
\hline 20.949 & 0.646 & 1.889 & 0.753 & 3.889 & .1 \\
\hline 29.110 & 0.728 & 1.454 & 0.721 & 4.324 & .2 \\
\hline 23.591 & 0.514 & 1.750 & 0.960 & 4.222 & .3 \\
\hline 23.708 & 0.553 & 1.741 & 0.782 & 3.926 & .4 \\
\hline 29.679 & 0.714 & 1.435 & 0.726 & 4.343 & .5 \\
\hline 23.678 & 0.500 & 1.741 & 0.949 & 4.185 & .6 \\
\hline 26.138 & 0.483 & 1.639 & 0.753 & 3.889 & .7 \\
\hline 36.117 & 0.554 & 1.463 & 0.662 & 4.463 & .8 \\
\hline 23.798 & 0.569 & 1.648 & 0.946 & 4.176 & .9 \\
\hline 24.863 & 0.411 & 1.787 & 0.759 & 3.852 & .10 \\
\hline
\end{tabular}

علاقة الفقرة بالارجة الكلية للمقياس:-

حسب معامل ارتباط بيرسون بين درجة كل فقرة من فقرات مقياس

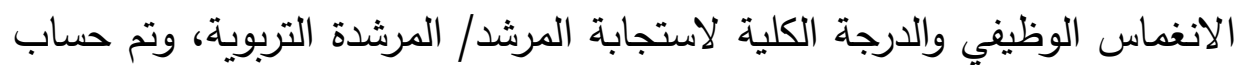


القيمة التائية لمعامل الارتباط لكل فقرة، فتبين أن جميع الفقرات ذات دلالة

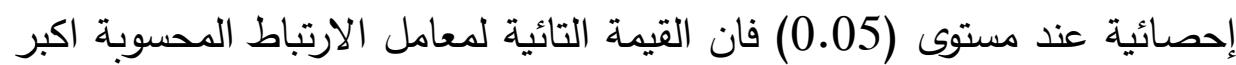

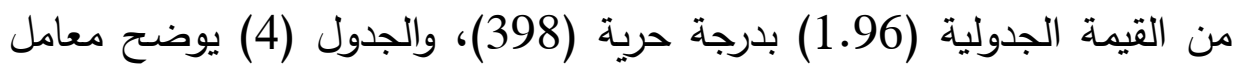

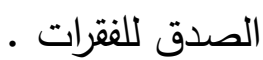

الجدول (4) معاملات الصدق لفقرات مقياس الانغماس الوظيفي

\begin{tabular}{|c|c|c|}
\hline القيمة التائية & معامل الارتباط & ت \\
\hline 24.47 & 0.775 & 1 \\
\hline 22.15 & 0.743 & 2 \\
\hline 27.86 & 0.813 & 3 \\
\hline 23.55 & 0.763 & 4 \\
\hline 17.29 & 0.655 & 5 \\
\hline 27.65 & 0.811 & 6 \\
\hline 34.55 & 0.866 & 7 \\
\hline 29.12 & 0.825 & 8 \\
\hline 24.87 & 0.780 & 9 \\
\hline 30.52 & 0.837 & 10 \\
\hline
\end{tabular}

ثبات المقياس: تحقق الباحث من ثبات مقياس الانغماس الوظيفي

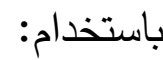
الاتساق الاخلي باستخدام معادلة الفاكروبناخ: 
إن الثبات بالاتساق الداخلي يقوم على العلاقة بين كل فقرة وفقرة أخرى من فقرات المقياس، وتستخدم دعادلة ألفا كروبناخ، لأنه أسلوب دقيق لقياس معامل

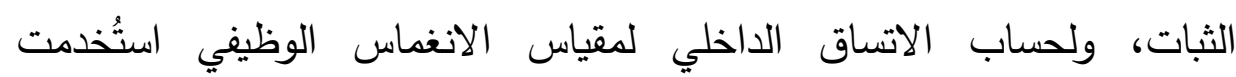
استجابات عينة التحليل الإحصائي في حساب الثبات، و بلغ معامل ألفا كرونباخ (0.91) ويعد معامل ثبات ممتاز للاتساق الداخلي لمقياس الانغماس الوظيفي.

\section{مقياس الانغماس الوظيفي بصيغته النهائية:}

بلغ عدد الفقرات الكلي لمقياس الانغماس الوظيفي بصيغته النهائية (10) فقرات. وحددت بدائل الاستجابة عن فقرات المقياس و أوزانها، يتدرج من موافق بشدة (5) إلى غير موافق بشدة (1). وأعلى درجة للمقياس (50) وأدنى درجة (10) بمتوسط نظري (30).

\section{ثانيا: مقياس الإزعاجات اليومية:}

لقياس الإزعاجات اليومية لدى المرشدين التربوين (الذكور/ الإناث) قام

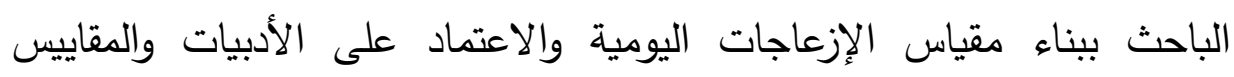
السابقة، فقد صاغ عدد من الفقرات لمقياس الإزعاجات اليومية ومتكون من (5) مجالات، إذ بلغ عدد الكلي لفقرات للمقياس في صورته الأولية (50) فقرة. المجال الأول: إزعاجات الوقت. ويتكون من (10) فقرات. المجال الثاني: إزعاجات العمل ويتكون من (10) فقرات. المجال الثالث: المسؤوليات الأسرية ويتكون من (10) فقرات المجال الرابع: الإزعاجات الاجتماعية ويتكون من (10) فقرات. المجال الخامس: المسؤوليات المالية ويتكون من (10) فقرات. 


\section{مجلة وادي النيل للاراسات والبحوث الإنسانية والاجتماعية ـ مجلة علمية محكمة}

(ISSN : 2536 - 9555)

تم تحديد بدائل الاستجابة على فقرات المقياس و أوزانها، وكانت البدائل

هي (تحدث دائماً، تحدث غالباً، تحدث أحياناً، تحدث نادراً، لا تحدث أبداً).

صدق المقياس: ولغرض التأكد من قوة وملائمة صياغة الفقرات ومدى ملائمتها للمجالات الفرعية، تم عرض الفقرات على مجموعة من الخبراء و المحكمين المختصين في العلوم النفسية، إذ تم إجراء بعض التعديلات وبضمنها تعديلات لغوية بسيطة، ولم يتم حذف فقرات من المجالات وبقيت (50) فقرة، وتثير الدرجة العالية على المقياس إلى ارتفاع تأثير الإزعاجات اليومية، و تمثل الدرجة الواطئة إلى انخفاض تأثير الإزعاجات اليومية لدى المرشدين التربويين (الذكور)

التجربة الاستطلاعية:

- التحليل الإحصائي لفقرات مقياس الإزعاجات اليومية:

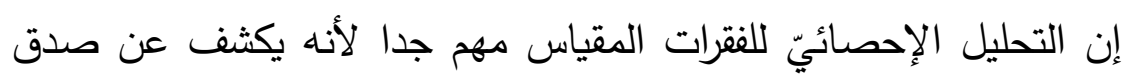
الفقرات على نحو دقيق ( فرج، 1980: 331-332 ) و يؤكد خبراء القياس النفسي على أهمية الخصائص السيكومترية التي يجب التحقق منها في فقرات المقاييس و هي قوة تمييز الفقرات ومعاملات صدقها، لذلك تم حساب هذه

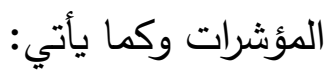

\section{القوة التمييزية لفقرات مقياس الإزعاجات اليومية:}

لتحقيق ذلك طبق مقياس الإزعاجات اليومية على عينة سحبت من مجتمع البحث مكونة من (400) مرشد/ مرشدة تربوية. فقد أشار هنريسون انه يفضل إن يكون (400) حجم العينة المناسب في عملية التحليل الإحصائي لحساب قوة تمييز الفقرات، إذ في حالة اعتماد نسبة (27\%) من أفراد العينة في تحديد المجموعتين المتطرفتين في الدرجة الكلية، يتحقق حجم مناسب في كل مجموعة 
وتباين جيد بينها (Henrysoon, 1971: p.132). بعد تطبيق مقياس

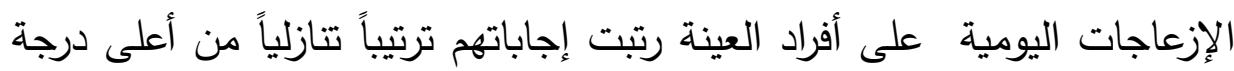
كلية إلى أقل درجة كلية، و حددت المجموعتان المتطرفتان في الدرجة الكلية بنسبة (27\%) من المرشدين التربويين عينة التمييز في كل مجموعة، فأصبح عدد المرشدين / المرشدات التربويات في كل مجموعة (108) مرشد /مرشدة التدين

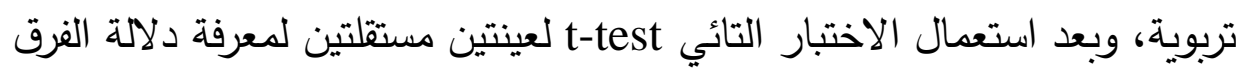

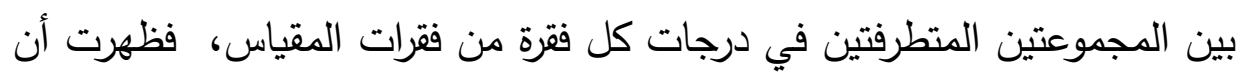

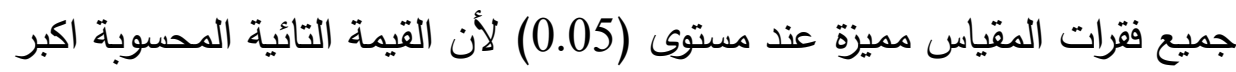

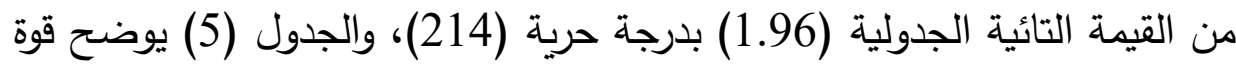
تمييز الفقرات لدقياس الإزعاجات اليومية.

الجدول (5) قوة تمييز الفقرات لمقياس الإزعاجات اليومية

\begin{tabular}{|c|c|c|c|c|c|}
\hline \multirow{2}{*}{ القيمة التائية } & \multicolumn{2}{|c|}{ المجموعة الدنيا } & \multicolumn{2}{|c|}{ المجموعة العليا } & \multirow[t]{2}{*}{ 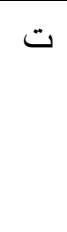 } \\
\hline & الانحراف المعياري & الحستوسط الحسب & الانحراف & الحستوسطي & \\
\hline 36.815 & 0.553 & 1.454 & 0.648 & 4.472 & .1 \\
\hline 30.027 & 0.785 & 1.333 & 0.708 & 4.389 & .2 \\
\hline 24.611 & 0.557 & 1.630 & 0.961 & 4.259 & .3 \\
\hline 21.355 & 0.666 & 1.796 & 0.794 & 3.926 & .4 \\
\hline 34.669 & 0.603 & 1.528 & 0.648 & 4.481 & .5 \\
\hline 24.955 & 0.557 & 1.769 & 0.920 & 4.352 & .6 \\
\hline 23.369 & 0.688 & 1.556 & 0.826 & 3.972 & .7 \\
\hline 35.967 & 0.498 & 1.435 & 0.696 & 4.398 & .8 \\
\hline 25.525 & 0.483 & 1.806 & 0.922 & 4.361 & .9 \\
\hline 23.973 & 0.585 & 1.648 & 0.800 & 3.935 & .10 \\
\hline
\end{tabular}


مجلة وادي النيل للاراسات والبحوث الإنسانية والاجتماعية ـ مجلة علمية محكمة

(ISSN : 2536 - 9555)

\begin{tabular}{|c|c|c|c|c|c|}
\hline 30.222 & 0.637 & 1.620 & 0.686 & 4.343 & .11 \\
\hline 30.436 & 0.716 & 1.472 & 0.696 & 4.398 & .12 \\
\hline 26.298 & 0.523 & 1.685 & 0.923 & 4.370 & .13 \\
\hline 26.027 & 0.474 & 1.667 & 0.819 & 4.037 & .14 \\
\hline 45.344 & 0.514 & 1.417 & 0.524 & 4.620 & .15 \\
\hline 20.309 & 0.582 & 1.815 & 0.971 & 4.028 & .16 \\
\hline 22.048 & 0.618 & 1.861 & 0.785 & 3.981 & .17 \\
\hline 30.027 & 0.785 & 1.333 & 0.708 & 4.389 & .18 \\
\hline 23.370 & 0.550 & 1.843 & 0.938 & 4.287 & .19 \\
\hline 24.082 & 0.545 & 1.759 & 0.809 & 4.019 & .20 \\
\hline 30.436 & 0.716 & 1.472 & 0.696 & 4.398 & .21 \\
\hline 23.518 & 0.662 & 1.694 & 0.940 & 4.296 & .22 \\
\hline 22.651 & 0.681 & 1.676 & 0.820 & 4.000 & .23 \\
\hline 28.103 & 0.802 & 1.454 & 0.716 & 4.361 & .24 \\
\hline 21.731 & 0.779 & 1.694 & 0.936 & 4.241 & .25 \\
\hline 23.432 & 0.646 & 1.648 & 0.809 & 3.981 & .26 \\
\hline 25.045 & 0.929 & 1.417 & 0.752 & 4.296 & .27 \\
\hline 24.516 & 0.538 & 1.694 & 0.936 & 4.241 & .28 \\
\hline 26.490 & 0.550 & 1.574 & 0.924 & 4.315 & .29 \\
\hline 25.807 & 0.637 & 1.380 & 0.799 & 3.917 & .30 \\
\hline 25.464 & 0.729 & 1.806 & 0.719 & 4.315 & .31 \\
\hline 18.354 & 0.775 & 1.843 & 0.984 & 4.056 & .32 \\
\hline 21.638 & 0.633 & 1.861 & 0.809 & 4.000 & .33 \\
\hline 32.961 & 0.642 & 1.407 & 0.699 & 4.417 & .34 \\
\hline 21.887 & 0.737 & 1.787 & 0.942 & 4.306 & .35 \\
\hline 16.070 & 1.007 & 1.935 & 0.773 & 3.898 & .36 \\
\hline 22.554 & 0.949 & 1.657 & 0.747 & 4.278 & .37 \\
\hline
\end{tabular}




\begin{tabular}{|c|c|c|c|c|c|}
\hline 18.657 & 0.870 & 1.833 & 0.959 & 4.157 & .38 \\
\hline 24.460 & 0.597 & 1.593 & 0.787 & 3.917 & .39 \\
\hline 30.235 & 0.726 & 1.426 & 0.705 & 4.370 & .40 \\
\hline 18.427 & 0.928 & 1.787 & 0.955 & 4.148 & .41 \\
\hline 27.096 & 0.891 & 1.472 & 0.700 & 4.426 & .42 \\
\hline 26.984 & 0.878 & 1.426 & 0.718 & 4.370 & .43 \\
\hline 31.209 & 0.711 & 1.287 & 0.723 & 4.333 & .44 \\
\hline 28.070 & 0.832 & 1.333 & 0.736 & 4.333 & .45 \\
\hline 21.161 & 0.669 & 1.898 & 0.936 & 4.241 & .46 \\
\hline 21.524 & 0.633 & 1.806 & 0.799 & 3.917 & .47 \\
\hline 28.062 & 0.728 & 1.454 & 0.741 & 4.259 & .48 \\
\hline 21.034 & 0.717 & 1.833 & 0.943 & 4.231 & .49 \\
\hline 17.047 & 0.929 & 1.917 & 0.773 & 3.898 & .50 \\
\hline
\end{tabular}

علاقة الفقرة بالدرجة الكلية لمقياس الإزعاجات اليومية:

تكون الفقرة صادقة إذا كان معامل ارتباطها بالدرجة الكلية عالياً، فحسب معامل ارتباط بيرسون بين درجة كل فقرة والدرجة الكلية على مقياس الإزعاجات اليومية ثم حسبت القيمة التائية لمعامل الارتباط لكل فقرة، فأتضح أن جميع الفقرات ذات دلالة إحصائية عند مستوى (0.05) لأن القيمة التائية لدلالة معامل الارتباط المحسوبة اكبر من القيمة الجدولية (1.96) بدرجة حرية (398)، والجدول (6) يوضح معامل صدق الفقرات .

الجدول (6) معاملات صدق فقرات مقياس الإزعاجات اليومية

\begin{tabular}{|c|c|c|c|c|}
\hline الدلالة المعنوية & الارتباط معامل & الدعنولة الدلة & الارتباط معامل & ت \\
\hline 27.36 & 0.808 & 38.32 & 0.887 & 1 \\
\hline 27.07 & 0.805 & 35.37 & 0.871 & 2 \\
\hline
\end{tabular}


مجلة وادي النيل للاراسات والبحوث الإنسانية والاجتماعية ـ مجلة علمية محكمة

(ISSN : 2536 - 9555)

\begin{tabular}{|r|l|l|l|r|}
\hline 33.77 & 0.861 & 30.04 & 0.833 & 3 \\
\hline 32.75 & 0.854 & 26.79 & 0.802 & 4 \\
\hline 32.47 & 0.852 & 35.20 & 0.870 & 5 \\
\hline 30.89 & 0.840 & 28.80 & 0.822 & 6 \\
\hline 23.11 & 0.757 & 24.70 & 0.778 & 7 \\
\hline 24.23 & 0.772 & 31.52 & 0.845 & 8 \\
\hline 29.46 & 0.828 & 34.55 & 0.866 & 9 \\
\hline 27.07 & 0.805 & 32.47 & 0.852 & 10 \\
\hline 16.75 & 0.643 & 31.79 & 0.847 & 11 \\
\hline 21.00 & 0.725 & 27.07 & 0.805 & 12 \\
\hline 22.62 & 0.750 & 32.19 & 0.850 & 13 \\
\hline 26.51 & 0.799 & 31.92 & 0.848 & 14 \\
\hline 28.16 & 0.816 & 38.94 & 0.890 & 15 \\
\hline 18.81 & 0.686 & 26.42 & 0.798 & 16 \\
\hline 22.28 & 0.745 & 26.97 & 0.804 & 17 \\
\hline 26.24 & 0.796 & 35.37 & 0.871 & 18 \\
\hline 25.53 & 0.788 & 31.65 & 0.846 & 19 \\
\hline 20.40 & 0.715 & 26.88 & 0.803 & 20 \\
\hline 23.55 & 0.763 & 27.07 & 0.805 & 21 \\
\hline 18.30 & 0.676 & 27.56 & 0.810 & 22 \\
\hline 16.23 & 0.631 & 27.26 & 0.807 & 23 \\
\hline 24.47 & 0.775 & 31.26 & 0.843 & 24 \\
\hline 22.08 & 0.742 & 24.00 & 0.769 & 25 \\
\hline & & & & \\
\hline
\end{tabular}

حسبت علاقة درجة الفقرة بالمجال الذي تتنمي إليه، باستعمال معامل ارتباط بيرسون, وحسبت الدلالة المعنوية لمعامل الارتباط للفقرات,وقد بينت النتائج

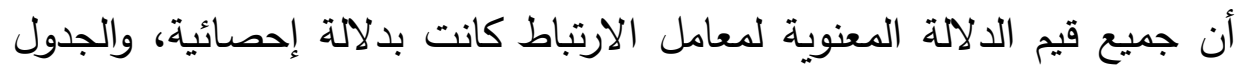

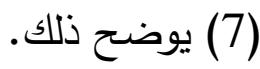


الجدول ( 7 ) معاملات الارتباط بين كل فقرة والدرجة الكلية للمجال الذي تنتمي إليه

والدلالة المعنوية لمقياس الإزعاجات اليومية

\begin{tabular}{|c|c|c|c|}
\hline القيمة التائية & معامل الارتباط & المجال & ت \\
\hline 37.34 & 0.882 & \multirow{10}{*}{ إزعاجات الوقت } & 1 \\
\hline 32.61 & 0.853 & & 2 \\
\hline 28.80 & 0.822 & & 3 \\
\hline 25.45 & 0.787 & & 4 \\
\hline 32.19 & 0.85 & & 5 \\
\hline 25.62 & 0.789 & & 6 \\
\hline 22.83 & 0.753 & & 7 \\
\hline 28.16 & 0.816 & & 8 \\
\hline 32.05 & 0.849 & & 9 \\
\hline 31.92 & 0.848 & & 10 \\
\hline 30.03 & 0.833 & \multirow{10}{*}{ إزعاجات العمل } & 11 \\
\hline 25.11 & 0.783 & & 12 \\
\hline 29.68 & 0.830 & & 13 \\
\hline 30.78 & 0.839 & & 14 \\
\hline 37.82 & 0.884 & & 15 \\
\hline 23.37 & 0.761 & & 16 \\
\hline 26.66 & 0.801 & & 17 \\
\hline 33.49 & 0.859 & & 18 \\
\hline 28.58 & 0.820 & & 19 \\
\hline 25.21 & 0.784 & & 20 \\
\hline 27.84 & 0.813 & \multirow{5}{*}{ المسؤوليات الأسرية } & 21 \\
\hline 21.24 & 0.729 & & 22 \\
\hline 21.94 & 0.740 & & 23 \\
\hline 26.92 & 0.803 & & 24 \\
\hline 23.48 & 0.762 & & 25 \\
\hline
\end{tabular}


مجلة وادي النيل للاراسات والبحوث الإنسانية والاجتماعية ـ مجلة علمية محكمة

(ISSN : 2536 - 9555)

\begin{tabular}{|c|c|c|c|}
\hline 15.97 & 0.625 & & 26 \\
\hline 20.07 & 0.709 & & 27 \\
\hline 21.77 & 0.737 & & 28 \\
\hline 23.28 & 0.759 & & 29 \\
\hline 26.00 & 0.793 & & 30 \\
\hline 21.87 & 0.739 & \multirow{10}{*}{ الإزعاجات الاجتماعية } & 31 \\
\hline 28.39 & 0.818 & & 32 \\
\hline 24.63 & 0.777 & & 33 \\
\hline 28.16 & 0.816 & & 34 \\
\hline 27.45 & 0.809 & & 35 \\
\hline 26.92 & 0.803 & & 36 \\
\hline 25.83 & 0.791 & & 37 \\
\hline 36.87 & 0.880 & & 38 \\
\hline 30.59 & 0.838 & & 39 \\
\hline 28.43 & 0.819 & & 40 \\
\hline 15.16 & 0.605 & \multirow{10}{*}{ المسؤوليات المالية } & 41 \\
\hline 26.29 & 0.797 & & 42 \\
\hline 28.37 & 0.818 & & 43 \\
\hline 28.07 & 0.815 & & 44 \\
\hline 24.25 & 0.772 & & 45 \\
\hline 19.90 & 0.706 & & 46 \\
\hline 18.92 & 0.688 & & 47 \\
\hline 19.96 & 0.707 & & 48 \\
\hline 19.47 & 0.698 & & 49 \\
\hline 16.88 & 0.646 & & 50 \\
\hline
\end{tabular}

ثبات المقياس: تحقق الباحث من ثبات مقياس الإزعاجات اليومية بطريقة الاتساق الداخلي باستخدام معادلة ألفا كروبناخ ولتقدير الاتساق الداخلي لمقياس الإزعاجات اليومية استعمل الباحث استجابات عينة التحليل الإحصائي في حساب 
الثبات وقد بلغ معامل ألفا (0.83) وهو معامل ثبات موثوق به للاتساق الداخلي للمقياس .

مقياس الإزعاجات اليومية بصيفته النهائية: بلغ عدد الفقرات الكلي لدقياس

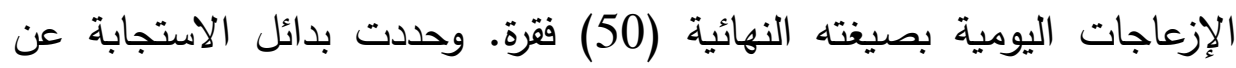

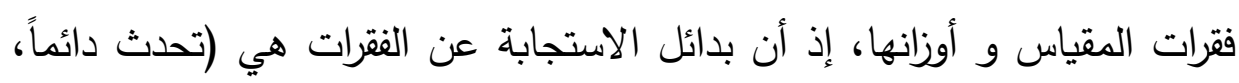

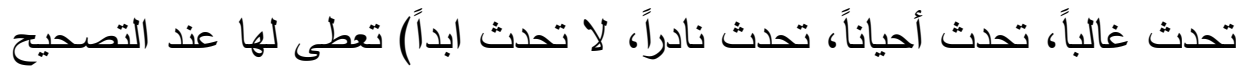

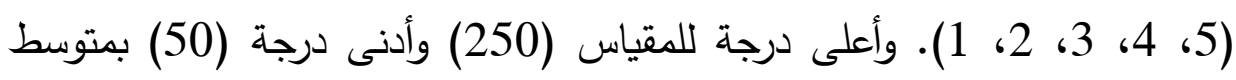
نظري (150).

تطبيق مقياسي البحث: بعد إعداد مقياس الانغماس الوظيفي و مقياس

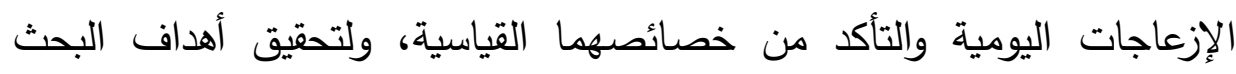
الحالي، تم تطبيقه على أفراد عينة البحث الأساسية من المشردين التربويين والبالغة (200) مرشد/ مرشدة تربوية, انظر الجدول(1). الوسائل الإحصائية: استُخدمت الوسائل الإحصائية الآتية:-

(t-test)

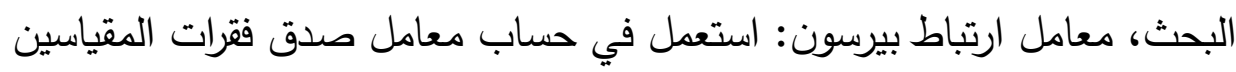

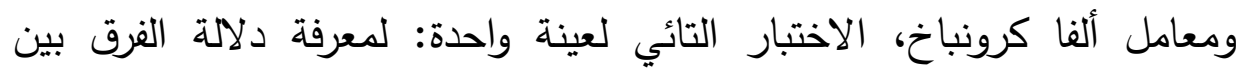

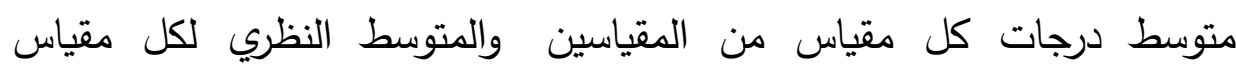
لعينتين مستقلتين: استعمل لمعرفة دلالة الفروق في الsقياسين تبعاً (t-test) لمتغير الجنس. عرض النتائج وتفسيرها: 1-الهذف الأول: لقياس مستوى الانغماس الوظيفي لدى المشدين التربويين، وتحقيقاً لذلك استعمل الباحث الاختبار التائي لعينة واحدة (T-test)، 
وأظهرت النتائج أن متوسط درجات الانغماس الوظيفي لعينة البحث يساوي

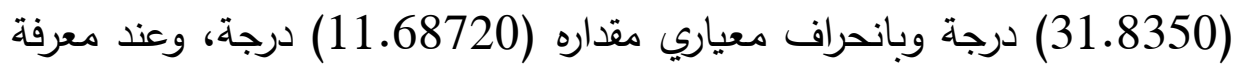

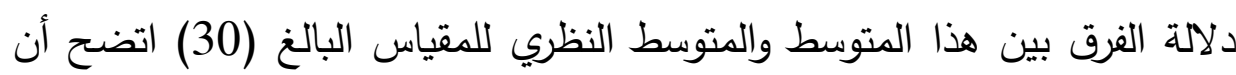
الفرق كان بدلالة إحصائية عند مستوى (0.05) إذ بلغت القيمة التائية المحسوبة (2.220) وهي أكبر من القيمة التائية الجدولية (1.96) بدرجة حرية (199) (190)، والجدول (8) يوضح ذلك.

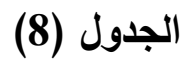

نتيجة الاختبار التائي لارجات العينة على مقياس الانغماس الوظيفي

\begin{tabular}{|c|c|c|c|c|c|c|c|}
\hline مستوى & \multicolumn{2}{|c|}{ القيمة التائية } & \multirow{2}{*}{ درية } & \multirow{2}{*}{ المعياري } & \multirow{2}{*}{ متوسطة } & \multirow{2}{*}{ النظتوسط } & \multirow[t]{2}{*}{ العينة } \\
\hline & الجدولية & المحسوبة & & & & & \\
\hline 0.05 & 1.96 & 2.220 & 99 & 11.68720 & 31.3850 & 30 & 200 \\
\hline
\end{tabular}

أظهرت النتيجة وجود فرق دال إحصائيا بين متوسط العينة و المتوسط

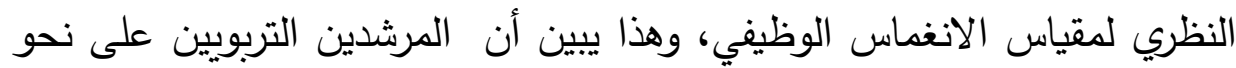

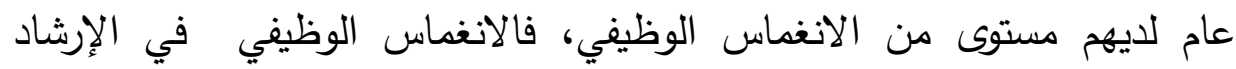

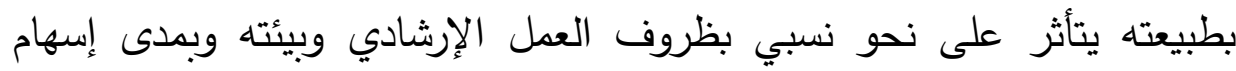

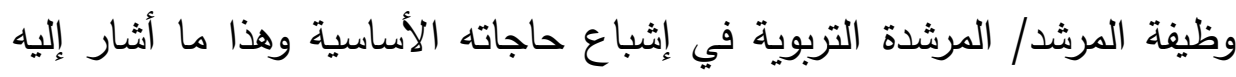
.(Kanungo, 1982)

2-الهدف الثاني: خصص الهدف الثاني لقياس مستوى الإزعاجات اليومية

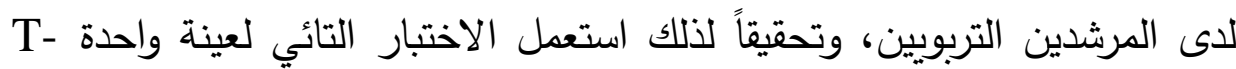

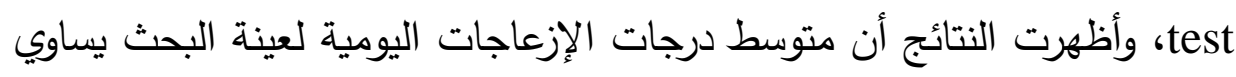

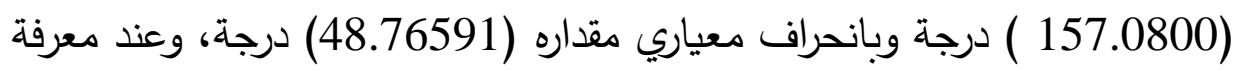

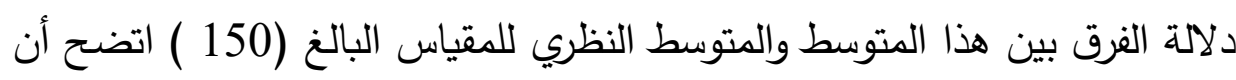


الفرق كان بدلالة إحصائية عند مستوى (0.05) إذ بلغت القيمة التائية المحسوبة

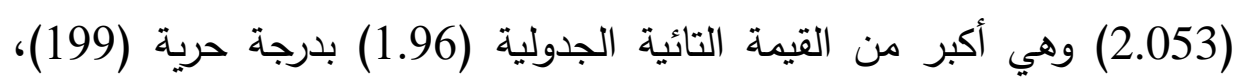
والجدول ( ) يوضح ذلك.

الجدول (9)

نتيجة الاختبار التائي لارجات العينة على مقياس الازعاجات اليومية

\begin{tabular}{|c|c|c|c|c|c|c|c|}
\hline مستوى & \multicolumn{2}{|c|}{ القيمة التائية } & \multirow{2}{*}{ درجة } & \multirow{2}{*}{ الانحراف } & \multirow{2}{*}{ متوسط العينة } & \multirow{2}{*}{ النظتوسط } & \multirow[t]{2}{*}{ لعينة } \\
\hline & الجدولية & المحسوبة & & & & & \\
\hline 0.05 & 1.96 & 2.053 & 99 & 48.76591 & 157.080 & 1.5 & 200 \\
\hline
\end{tabular}

وتعزى هذه النتيجة إلى أن المرشدين التربويين لديهم على نحو عام مستوى التحى

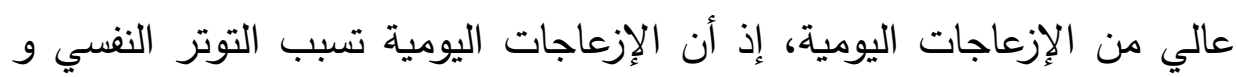

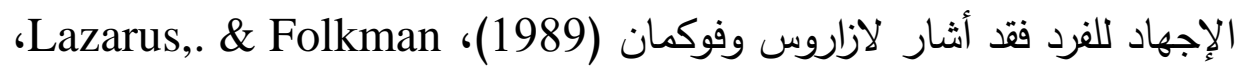

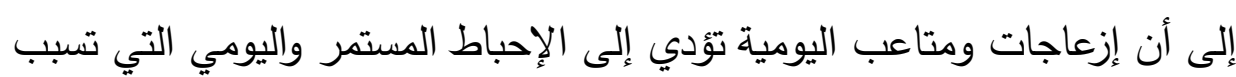

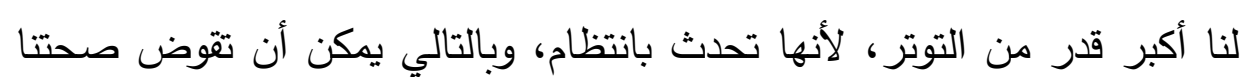
الجسدية والنفسية.

3-الهذف الثالث: التعرف على العلاقة بين الانغماس الوظيفي والإزعاجات

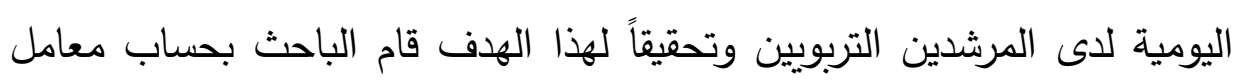

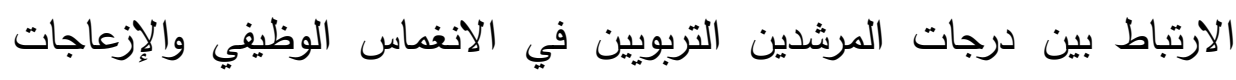

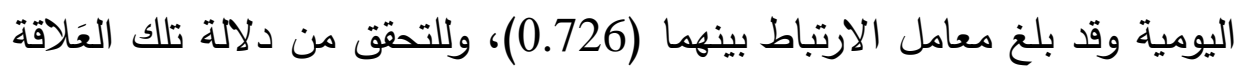

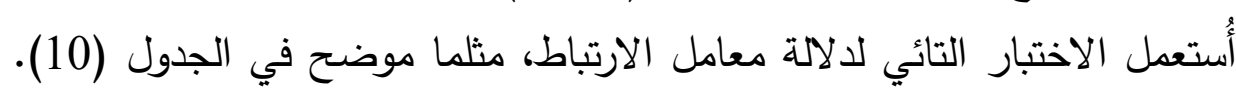

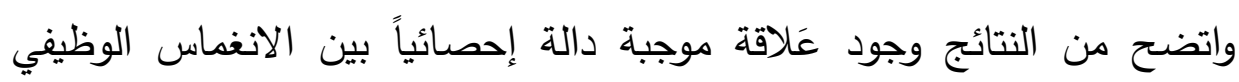
والإزعاجات اليومية. 
مجلة وادي النيل للاراسات والبحوث الإنسانية والاجتماعية ـ مجلة علمية محكمة

(ISSN : 2536 - 9555)

الجدول (10) معامل الارتباط بين الانغماس الوظيفي والإزعاجات اليومية لدى

المرشدين التربويين

\begin{tabular}{|c|c|c|c|}
\hline \multicolumn{2}{|c|}{ القيمة التائية } & \multirow{2}{*}{ معامل الارتباط } & \multirow{2}{*}{ المتغيرات } \\
\hline الجدولية & المحسوبة & & \\
\hline \multirow{2}{*}{1.96} & \multirow{2}{*}{14.86} & \multirow{2}{*}{0.726} & الانغماس الوظيفي \\
\hline & & & الإزعاجات اليومية \\
\hline
\end{tabular}

واتضح من النتيجة وجود عَلاقة موجبة دالة إحصائياً بين الانغماس

الوظيفي والازعاجات اليومية، إن استمرار تلك الإزعاجات و المتاعب يؤدي بالمرشد التربوي إلى الانسحاب من الحياة اليومية و الاجتماعية و التفاعل المهني، ويفقده الاهتمام بالمشاركات و التفاعل مع الآخرين، إن ارتفاع مستوى التوترات و المتاعب والازعاجات اليومية يصل بالمرشد النفسي إلى حالة من الاعتلال النفسي الذي يؤدي إلى مستويات مرتفعة من اللامبالاة وعدم الاهتمام بمهنته، وقلة الدافعية لديه و فقدان القدرة على التفاعل مع الآخرين، و التصرف الته على نحو يفتقر للاندماج الذاتي في العمل الإرشادي.

4- الهُف الرابع: خصص الهدف الرابع لقياس درجة الانغماس الوظيفي المرشدين التربوين و بحسب متغير (الجنس) فقد استعمل الاختبار التائي لعينتين مستقلتين، والجدول (11) يوضح ذلك. الجدول (11) الاختبار التائي لعينتين مستقلتين لالالة الفروق بين متوسط (الأكور، الإناث) في مقياس الانغماس الوظيفي للمرشدين التربويين

\begin{tabular}{|c|c|c|c|c|c|c|c|}
\hline \multirow{2}{*}{ مستوى } & \multicolumn{2}{|c|}{ القيمة التائية } & \multirow{2}{*}{ الحرية } & \multirow{2}{*}{ المعياري } & \multirow{2}{*}{ الصسابي } & \multirow[b]{2}{*}{ العدد } & \multirow[b]{2}{*}{ العينة } \\
\hline & الجدولية & المحسوبة & & & & & \\
\hline \multirow{2}{*}{ غير دالة } & \multirow{2}{*}{1.96} & \multirow{2}{*}{0.079} & \multirow{2}{*}{198} & 12.02583 & 31.7465 & 71 & الذكور \\
\hline & & & & 11.54382 & $\mathbf{3 1 . 8 8 3 7}$ & 129 & الإناث \\
\hline
\end{tabular}


يلاحظ من الجدول (11) انه لا توجد فروق ذات دلالة إحصائية في

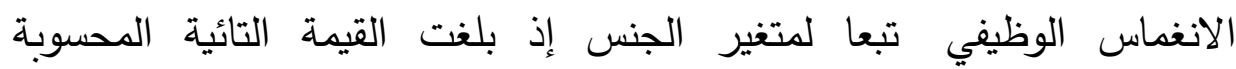

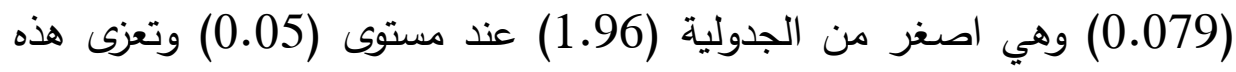

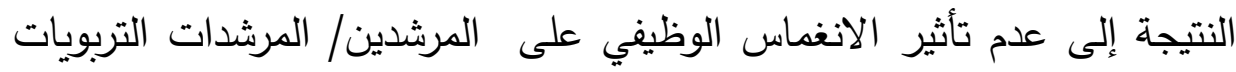

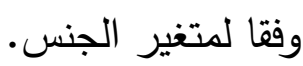

5- الهدف الخامس: خص الهدف الخامس لقياس مستوى الإزعاجات اليومية لاى المشدين التربويين و بحسب متغير ( الجنس). فقد استعمل الاختبار

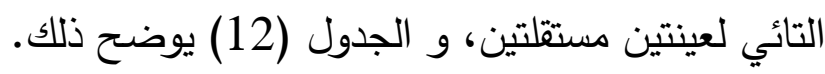

الجدول (12) الاختبار التائي لعينتين مستقلتين لدلالة الفروق بين متوسط (الذكور ،

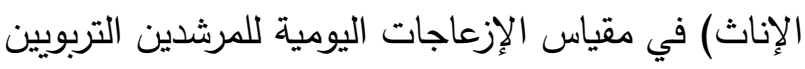

\begin{tabular}{|c|c|c|c|c|c|c|c|}
\hline \multirow{2}{*}{ مستوى } & \multicolumn{2}{|c|}{ القيمة التائية } & \multirow{2}{*}{ درجة } & \multirow{2}{*}{ الالحعراف } & \multirow{2}{*}{ الحسابي } & \multirow{2}{*}{ الأفراد عدد } & \multirow[t]{2}{*}{ العينة } \\
\hline & الجدولية & المحسوبة & & & & & \\
\hline \multirow[t]{2}{*}{ دال } & \multirow[t]{2}{*}{1.96} & \multirow[t]{2}{*}{3.408} & \multirow[t]{2}{*}{198} & 53.97833 & 141.6479 & 71 & الذكور \\
\hline & & & & 43.57766 & 165.5736 & 129 & الإناث \\
\hline
\end{tabular}

بما أن القيمة التائية المحسبة لمتغير الجنس (ذكور/أناث) والبالغة (3.408) اكبر من القيمة الجدولية البالغة (1.96) عند مستوى دلالة (0.05) إذ فئل يوجد فرق في مستوى الإزعاجات اليومية لاى المرشدين التربويين من الذكور

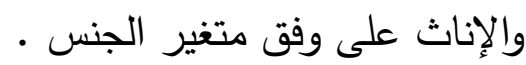

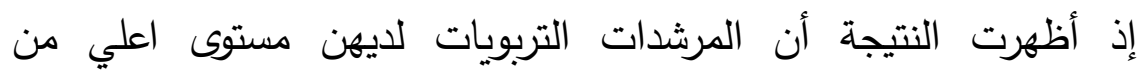

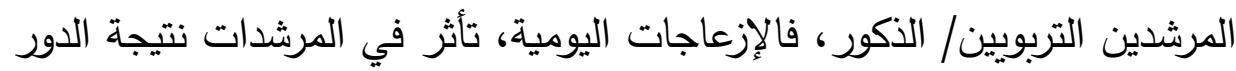
الذي تلعبه المرشدة كأم وأخت وبنت في أسرتها فرعاية الأسرة وتلبية احتياجاتهم 
وخاصة في مجتمعنا فضلا عن دورها كمشدة تربوية، كلها تزيد من تأثير الإزعاجات و المتاعب اليومية على الإناث أكثر من الذكور . الاستتتاجات: وفي ضوء نتائج البحث يستنتج الباحث ما يأتي: - لاى المرشدين التربوين مستوى من الانغماس الوظيفي كما ولديهم مستوى عالي من الإزعاجات اليومية. - عدم وجود أثر لمتغير الجنس في الانغماس الوظيفي لدى المرشدات التربويات مقارنة بالمرشدين التربوين/ الذكور، ولكن يوجد اثر في مستوى الإزعاجات اليومية لدى المرشدين التربويين يعزى لمتغير الجنس وعلى نحو خاص لدى المرشدات التربويات. - توجد علاقة ارتباطية داله بين الانغماس الوظيفي والإزعاجات اليومية لدى المرشدين التربوين. التوصيات: في ضـوء النتائج التي تم التوصل إليها، ومـا تم استتناجه يوصسي

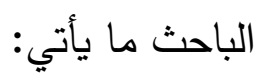

- عمل الندوات الدورية للمرشدين التربوين لبيان أهمية وظيفة المرشد التربوي وضرورة الانغماس بها لتلبية حاجات المرشدين وزيادة احترامهم لذواتهم. - تصميم البرامج الإرشادية والتدربية لرفع المستوى المهني والتحفيز الوظيفي للمرشدين التربوين وتحصينهم ضد الإزعاجات وحمايته من الإجهاد والتوتر النفسي.

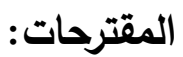
- إجراء دراسـة مماثلة عن تدريسي قسم الإرشـاد النفسي والتوجيـه التربوي لمتغيرات البحث الحالي ومقارنة نتائجها بالبحث الحالي. 
- إجراء دراسة مماثلة عن الانغماس الوظيفي وعلاقته بمتغيرات أخرى مثل الوحدة النفسية وغيرها.

- إجراء دراسـة مماثلـة عن الإزعاجـات اليوميـة وعلاقتها بمتغيرات أخرى مثل الانسحاب الاجتماعي وغيرها.

\section{المصادر:}

- بلـوم، بنيـامين وآخرون(1983) تقيـيم الطالب التجميعسي والتكـويني، ترجمـة: محمد أمين المفتي القاهرة، دار ماكجروجيل. لئل - الحراحشـة، سـالم احمود صـالح (2001)؛ تقويم الإزعاجـات اليوميـة للمرشدين

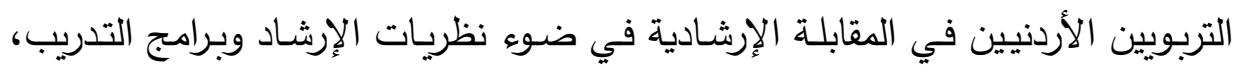
أطروحة دكتوراه(غير منشورة)، كلية التربية- أبن رشد، جامعة بغداد. - فرج، صفوت (1980) القياس النفسي، القاهرة: دار الفكر . - الفضـلي، فضلــ (2011): تأثير المتغيرات الديموغرافيـة والتوجهات القيميـة على الانغماس الوظيفي في القطاع الحكومي بدولة الكويت، مجلة جامعة الملك عبد

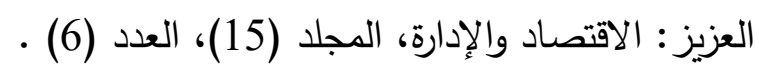
- قاسم، مرفت. (2012): نموذج ثلاثي الأبعاد للعلاقة بين جودة حياة العمل الوظيفية والالتزام التنظيمي والاستغراق في العمل: دراسـة ميدانية على العاملين بوزارة الداخلية، رسالة دكتوراه غير منشورة، جامعة عين شمس، القاهرة. - متولي، ماجده سـعد و هثـام سعيد عبد المجيد(1999) الارشـاد الاجتمـاعي اصوله النظريه وتطبيقاته العمليه، دار القلم للنشر ، دبي. - يوسف، هبة. (2001) علاقة بعض سمات الثخصية بالاستغراق (الانغماس)

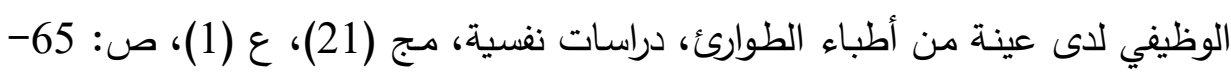

- Anastasi, A.(1997). Psychological testing ,7th ed New Jersey: Aivacom company . 
مجلة وادي النيل للاراسات والبحوث الإنسانية والاجتماعية ـ مجلة علمية محكمة

(ISSN : 2536 - 9555)

- Bass, B. M. (1965). Organizational psychology. Boston: Allyn \& Bacon

- Bhatie, A. , Deep, G. \& Sachdeva, S. (2012) . Analyzing the role of job involvement on organizational effectiveness, International journal of Computing \& Business research.

- Biddle, B. B., \& Thomas, E. J. (Eds.). (1966). Role theory: Concepts and research. New York: Wiley.

- Chamberlain, K., \& Zika, S. (1990). The minor events approach to stress: Support for the use of daily hassles. British Journal of Psychology, 81, 469-481.

- DeLongis, A., Folkman, S. \& Lazarus, R. (1988). The impact of daily stress on health and mood: Psychological and social resources as mediators. Journal of Personality and Social Psychology 54(3), 486-495.

- Elias, S. \& Mittal, R. (2011) . The importance of supervisor support for a change initiative: An analysis of job satisfaction and involvement, International Journal of Organizational Analysis. 19 (4) ,305- 316.

- Fink, George (2010). Stress Consequences: Mental, Neuropsychological and Socioeconomic, Mental Health Research Institute of Victoria Parkville. Melbourne: Victoria Australia.

- Garrison,M. E.(1990) The effect of daily hassles, reported managerial behavior, family adaptability and cohesion on family health, Iowa State University.

- Greenberg, M(2014) Find Relief From the Stress of Life's Daily Hassles, https://www.psychologytoday.com/blog/themindful-self-express/201410/find-relief-the-stress-lifes-dailyhassles.

- Henrysoon. (1971) "Gathering, Analyzing, and uising Data on Test Item" in Educational measurement Thorndike, R.I,2nd .ed.

- Kahn, W. A. (1990). Psychological conditions of personal engagement and disengagement at work. Ac a. of Management Journal, 33, 692-724.

- Kanner, A. D., Coyne, J. C., Schaefer, C., \& Lazarus, R. S. (1981). Comparison of two modes of stress measurement: daily 
hassles and uplifts versus major life events.Journal of Behavioral Medicine, 4(1), 1-39.

- Kanungo, R. D. (1982). Measurement of job and wori< Involvement. Joumal of Applied Psychology. 67 (3), 341-349.

- Khan, T. , Jam, F. \& Akbar, A. (2011) . Job involvement as predictor of employee commitment: Evidence from Pakistan, International Journal of Business \& Management, vol. 6, no. 4.

- Lawler, E.E., III. \& Hall, D.T. (1970). Relationship of job characteristics to job involvement, satisfaction and intrinsic motivation. Journal of Applied Psychology. 54, 305-312.

- Lazarus, Richard S. \& Folkman Susan,(1989). Stress: Appraisal and Coping, New York: Springer publishing Company.

- Leong, L. , Huang,S. Y. \& Hsu, j. (2003) . An empirical study on professional commitment, organizational commitment and job involvement in Canadian accounting firms, Journal of American Academy of Business, 2 (2), 360- 370.

- Malia, J. A., Ohuche, N., Norem, R. H., Allen, C. M., \& Bivens, G. (1987). Iowa Families Face the Rural Crisis. Family Environment Series, Vol. 2. Iowa state University. Ames, 1A.

- Paullay, I., Alliger, G., and Stone-Romero, E. (1994). Construct validation of two instruments designed to measure job involvement and work centrality. Journal of Applied Psychology, Vol. 79, pp. 224-8.

- Ranchor, A . \& Sanderman, R. (2000). Education Levels and Stress:Article from encyclopedia of stress. Netherlands: Academic press.

- Rich, bruce louis, and jeffrey a. lepine and eean r. crawford, (2010), job engagement: antecedents and effects on job performance, academy of management journal, vol. 53, no. 3, 617-635.

- Rothbard, N. P. (2001). Enriching or depleting? The dynamics of engagement in work and family roles. Administrative Science Quarterly, 46: 655-684.

- Siegel, A. E. (1969). Current issues in research on early development. Human Development, 12(2), 86-92.

- Sonnentag, S., \& Kruel, U. (2006). Psychological detachment from work during off-job time: The role of job stressors, job involvement, and recovery-related self-efficacy. 
European Journal of Work and Organizational Psychology, 15(2), 197-217.

- Spring, M., Ross, P., Etkin, N., \& Deinard, A. (1995). Sociocultural factors in the use of prenatal care by Hmong women in Minneapolis. American Journal of Public Health, 85. Retrievedfrom http://www.ncbi.nlm.nih.gov/pmc/articles/PMC1615525/.

- Stone, N. E. (2007). Somatic Awareness and Daily Hassles in Women with Acute Myocardial Infarction: Dissertation, University of Massachusetts, Medical School USA.

- Swaran, S., Islam, Md. And Yusuf, D. (2011). A study of the relationship between the big five personality dimensions and job Involvement in a foreign based financial institution in Penang. 